\title{
Article \\ Thermal Scaling of Transient Heat Transfer in a Round Cladded Rod with Modern Dimensional Analysis
}

\author{
Botond-Pál Gálfi ${ }^{1}$, Ioan Száva ${ }^{2}{ }^{\circledR}$, Daniela Șova ${ }^{2, *}$ and Sorin Vlase ${ }^{2,3, *}$ \\ 1 Autolive Romania, Brașov, Bucegi, Str. 8, 500053 Brașov, Romania; janoska@clicknet.ro \\ 2 Department of Mechanical Engineering, Transilvania University of Brașov, B-dul Eroilor 20, \\ 500036 Brașov, Romania; eet@unitbv.ro \\ 3 Romanian Academy of Technical Sciences, Bulevardul Dacia 26, 030167 Bucharest, Romania \\ * Correspondence: sova.d@unitbv.ro (D.S..); svlase@unitbv.ro (S.V.); Tel.: +40-722-643-020 (S.V.)
}

Citation: Gálfi, B.-P.; Száva, I.; Șova,

D.; Vlase, S. Thermal Scaling of

Transient Heat Transfer in a Round

Cladded Rod with Modern

Dimensional Analysis. Mathematics

2021, 9, 1875. https://doi.org/

$10.3390 /$ math9161875

Academic Editor:

Sergey Dashkovskiy

Received: 18 June 2021

Accepted: 2 August 2021

Published: 6 August 2021

Publisher's Note: MDPI stays neutral with regard to jurisdictional claims in published maps and institutional affiliations.

Copyright: (c) 2021 by the authors. Licensee MDPI, Basel, Switzerland. This article is an open access article distributed under the terms and conditions of the Creative Commons Attribution (CC BY) license (https:// creativecommons.org/licenses/by/ $4.0 /)$.

\begin{abstract}
Heat transfer analysis can be studied efficiently with the help of so-called modern dimensional analysis (MDA), which offers a uniform and easy approach, without requiring in-depth knowledge of the phenomenon by only taking into account variables that may have some influence. After a brief presentation of the advantages of this method (MDA), the authors applied it to the study of heat transfer in straight bars of solid circular section, protected but not thermally protected with layers of intumescent paints. Two cases (two sets of independent variables) were considered, which could be easily tracked by experimental measurements. The main advantages of the model law obtained are presented, being characterized by flexibility, accuracy, and simplicity. Additionally, this law and the MDA approach allow us to obtain much more advantageous models from an experimental point of view, with the geometric analogy of the model with the prototype not being a necessary condition. To the best knowledge of the present authors there are no studies reporting the application of the MDA method as it was used in this paper to heat transfer.
\end{abstract}

Keywords: geometric analogy; similarity theory; dimensional analysis; model law; heat transfer; straight bar

\section{Introduction \\ 1.1. General Considerations}

The idea of dimensional analysis and its practical application dates from the end of the 18th century. The introduction of fundamental units allowed for the creation of some theoretical bases for the application of dimensional analysis in the verification of the correctness of some obtained formulas.

The method of dimensional analysis was conceived and developed in the last century by mathematicians and engineers in order to facilitate experimental investigations of complex structures, as well as difficult to reproduce phenomena, through the easier study of their small-scale models.

This method involves attaching a model (usually scaled down) to the actual structure, called a prototype. The experimental and theoretical study will be carried out/performed on the model, and the results obtained will be transferred to the prototype based on the rigorous application of the model law, specific to dimensional analysis.

The law of the model consists of a finite and well-determined number of dimensionless variables, established by Buckingham's theorem, which have as a starting point precisely the set of variables that intervene in the description of the respective physical phenomenon.

In the classical version (classical dimensional analysis-CDA), obtaining the model law, involves following one of the following paths:

- by the direct application of Buckingham's theorem, presented in detail in the papers mentioned in the paper; 
- by applying the method of partial differential equations on the fundamental differential relations, which describe the phenomenon, when the initial variables are transformed into dimensionless quantities (through a normalization process) and by their appropriate grouping the desired dimensionless groups will result;

- identification of the complete form, but also the simplest of the equation (equations) that describe the phenomenon, which we will transform into dimensionless forms, from which the desired dimensionless groups will be identified.

These ways of obtaining the desired dimensionless groups, which in fact constitute the law of the model, represent quite a difficult and at the same time arbitrary method, which also presuppose the thorough knowledge of the pursued phenomenon.

Compared to these, the method called modern dimensional analysis (MDA) offers a unique and simple way to obtain the model law, requiring only the consideration of all variables that could have an influence on the phenomenon, which is a clear advantage to the MDA. In this case, the complete set of dimensionless groups is obtained, and thus the complete version of the model law.

From this complete variant, based on the exclusion of some physical or dimensional variables irrelevant to the studied phenomenon, will result the model law, which most accurately describes the model-prototype correlation. Thus, based on a unique and simple approach, those correlations will be established, i.e., the model law, which ensures the transfer of the information obtained on the model to the prototype.

In this paper, the authors established that only the law of the model, as shown in paragraph 3.2 (of the variant I studied), can be applied to a concrete case.

A series of papers present the advantages of dimensional analysis $[1,2]$ and the limitations of using this method [3,4]. The basic results in the application of this method have been obtained in recent decades [5-8]. The fundamentals of the method are consistently developed and used in applications [9-13].

From all the fields in which the method of dimensional analysis has been applied, we referred only to its application to heat transfer, which will be the subject of this article.

Some particular cases of heat transfer have been used in the literature. The complexity of a heat transfer problem is significantly reduced using the dimensional analysis method and transforming the problem in a scale-free form. For example, this method is used to study the dimensionless groups in irradiated particle-laden turbulence [14]. For such systems it is concluded that two dimensionless groups are important in the system's thermal response.

An experimental study on the convection heat transfer coefficient and pressure drop values of $\mathrm{CO}_{2}$ led to the use of the dimensional analysis technique to develop correlations between Nusselt numbers and pressure drops [15]. Other example of the dimensional analysis in the case of heat transfer are presented in the literature [16-20].

The complexity and nonlinearity of mechanical or thermal phenomena require a new approach regarding the correlation of experimental results with theoretical data, which requires the development of pertinent mathematical models [21]. The conventional analysis usually involves many trials and diagrams with measurement results.

\subsection{Dimensional Modelling, a Design Tool for Heat Transfer Analysis}

Starting from the geometric analogy, a first more efficient approach is given by the similarity theory [22,23], where alongside the prototype, the model-usually a small-scaled model-is defined. The governing equations applied to the prototype are obtained by means of the model's behavior [24,25]. The model must accurately reflect the behavior of the prototype. The similarity between prototype and model is structural or functional. The structural similarity highlights mainly the geometric similarity between prototype and model, while the functional similarity aims to find corresponding equations that describe both prototype and model. Additionally, geometric similarity supposes proportionality between length and angle equality for the prototype and model. Thus, homologous points, lines, surfaces, and volumes of the prototype and model can be defined. Functional 
similarity involves similar processes in both systems, prototype and model, that take place at similar times, i.e., the accomplishment of the similarity of all physical properties that govern the analyzed process. This kind of similarity can be kinematic or dynamic, and the phenomena occur so that, in homologous points, at homologous times, each dimension $\eta$ is characterized by a constant ratio between the values corresponding to the model and prototype, $S_{\eta}$. These dimensionless ratios, which are constant in time and space, are scale factors of the dimensions involved or similarity ratios. The scale factor $S_{\eta}$ is defined as the ratio between the value of the dimension corresponding to the model $\left(\eta_{2}\right)$ and the prototype, respectively $\left(\eta_{1}\right)$ :

$$
S_{\eta}=\frac{\eta_{2}}{\eta_{1}}[-],
$$

The reverse of $S_{\eta}$ represents the coefficient of transition from the original to the model [21]. There are as many scale factors as dimensions describing the phenomenon. Practically, the mathematical solution of the complex equations that theoretically describe the actual phenomenon is replaced by correlations between dimensionless parameters, which are obtained from the fundamental relations of the phenomenon by a suitable grouping of dimensions, called similarity parameters, such as $N u, R e, S t, P r$, etc. Therefore, the dimensions are replaced by the corresponding scale factors, multiplied by constants, and by an appropriate grouping, the similarity parameters are obtained, and correlations among them, such as $N u=f(\operatorname{Re}, P r, G r, \ldots)$, are also obtained. By means of experimental measurements, these correlations simplify the analysis performed and allow a reduction in the number of measurements in order to obtain important parameters of the phenomenon.

Among the basic theorems of similarity, two of them can be highlighted:

- for two similar phenomena the homologous dimensionless groups are the same;

- the conditions that are necessary and sufficient for two phenomena to present similarity are:

- to be of the same nature;

- to have the same determinant parameters of similarity;

- to have the same initial and boundary conditions.

In the case of complex phenomena, the number of dimensionless parameter scales of involved variables and correlations increases very much and therefore the similarity theory must be replaced by a more efficient method that is the dimensional analysis [26] The main aspects concerning the similarity theory and dimensional analysis are indicated in [27-30].

\subsection{Classical Dimensional Analysis (CDA)}

There is in this case a model that will be analyzed instead of the prototype, and as a result of the experiments carried out on the model, by means of dimensionless relations (dimensionless groups $\pi_{j}$ ), the behavior of the prototype can be predicted, obviously in conditions of similarity.

By using the $\pi_{j}$ groups, $C D A$ simplifies very much the experimental investigations and the graphical representations, and the results have a high degree of abstraction and generality. The works $[26,29]$ present in detail the main $\pi_{j}$ groups that describe thermal energy processes.

$C D A$ is not a substitute for experimental measurements and does not have the purpose of explaining physical phenomena; it aims to simplify and optimize the design of experiments by grouping measurable parameters of a phenomenon in dimensionless groups, defined by Buckingham's $\pi$ theorem. Both model and prototype obey in their behavior the conditions set out in the $\pi_{j}$ group.

By using $C D A$, the $\pi_{j}$ groups can be set in one of the following ways:

- $\quad$ by direct application of Buckingham's $\pi$ theorem;

- by applying the method of partial differential equations to fundamental differential relations that describe the phenomenon; the initial variables are transformed into 
dimensionless quantities and then, by their suitably grouping, the $\pi_{j}$ groups are obtained;

- by identifying the full form, but also the simplest equation(s) that describe the phenomenon, which will be transformed into dimensionless forms from which the desired $\pi_{j}$ groups will be selected.

According to $[24,29]$ the Buckingham's $\pi$ theorem has the following statement: the required number of independent dimensionless groups formed by combining the variables of a phenomenon is equal to the total number of these quantities minus the number of primary units of measurement that is necessary to express the dimensional relations of the physical quantities.

Consider a process that can be described by a set of independent parameters $y_{i}$, $i=1,2, \ldots, n$ by means of the general relation:

$$
f\left(y_{1}, y_{2}, y_{3}, \ldots, y_{n}\right)=0
$$

For describing the $n$ quantities, $m$ primary units of measurement are required and thus, from Buckingham's theorem, $(n-m)$ independent $\pi_{j}$ dimensionless groups can be formed that are able to describe the considered process. They are in a similar relation:

$$
F\left(\pi_{1}, \pi_{2}, \ldots, \pi_{n-m}\right)=0
$$

The set of relations is given by:

$$
\pi_{j}=F_{j}\left(\pi_{1}, \pi_{2}, \ldots, \pi_{n-m}\right), j=1,2, \ldots,(n-m),
$$

The functional relationship among the $\pi_{j}$ groups is obtained from trials.

As mentioned in [21], CDA involves three steps, namely:

1. the selection of parameters and primary units that can most accurately describe the phenomenon;

2. the determination of $\pi_{j}$ groups by identifying the exponents of the independent variables;

3. the experimental determination of the functional relations among the $\pi_{j}$ groups.

Thus, the $\pi_{j}$ groups are defined as products of the representative quantities that are involved in describing the phenomenon having unknown exponents $(a, b, c, \ldots)$. From the condition that all the $\pi_{j}$ groups are dimensionless (the sum of the exponents of each primary dimension must be zero), a system of equations will be obtained where the unknowns are the exponents. It is a multiple indeterminate system, where convenient values are given from the beginning to the exponents of the primary units, while the rest of the unknown exponents are determined from the solution of the system. Finally, the total number of $\pi_{j}$ groups will be obtained.

Unfortunately, all approaches of the CDA show several shortcomings. That is why the original method described in [31,32], called modern dimensional analysis $(M D A)$, is according to the authors, the most efficient and easy way to approach dimensional analysis.

\subsection{Objectives and Purpose of the Paper}

This paper represents a theoretical and experimental study on the implementation of modern dimensional analysis (MDA) in solving the problem of heat transfer, especially to the metal structures used in civil and industrial constructions, protected or unprotected with layers of intumescent paints. A fire protection, in addition to maintaining the flexibility of the original structure, leads both to maintaining the initial load-bearing capacity of the resistance structure for a longer time in case of fire and to increase the guaranteed time for evacuation of persons and property subjected to fire. Other recent studies concerning dimensional analysis are presented in [33-41].

In this article, the authors set out to achieve the following major objectives: 
- Comparative analysis of methods that use the analysis of the phenomenon on models instead of prototypes, such as geometric analogy, theory of similarity, and classical dimensional analysis;

- Brief presentation of the MDA method and its net advantages in the study of the prototype-model correlation;

- Application of MDA to the study of heat transfer of straight metal bars of full circular section (but with the possibility of extending these results to rings of annular section) protected or unprotected by layers of intumescent paints;

- In this sense, the laws of the model are presented, which govern the heat transfer in these thermally protected or unprotected bars, the application of which leads to a significant simplification of the analysis of this complex and important phenomenon.

The aim of the manuscript is to apply modern dimensional analysis to the heat transfer in a circular bar. The heat transfer in the bar is transitory. The bar is placed in air; therefore, the boundary condition is convection. The heat transfer coefficients were considered among the other variables in applying $M D A$. As indicated in the manuscript, when using $M D A$, the relations of the model law are correlations among variables that are involved in the phenomenon, and they must not be compared with the physical relations that describe the phenomenon. In contrast with the classical dimensional analysis, MDA considers the variables that might influence the phenomenon, without requiring a thorough knowledge of the phenomenon and the governing relations. The relations of the model law can be extended to bars with tubular section and structures of bars with annular cross-section. This is also an advantage in using $M D A$. To the best knowledge of the authors, the heat transfer in a circular bars described by $M D A$ has not been reported before in the literature.

\section{Method of Analysis in Modern Dimensional Analysis (MDA)}

In a physical relation there is a single dependent variable and a finite number of independent variables. The variables are denoted by $\left(H_{1}, H_{2}, H_{3}, \ldots\right)$, while their dimensions are denoted by $\left(h_{1}, h_{2}, h_{3}, \ldots\right)$. The derived dimensions are obtained from the combination of previously selected primary dimensions, such as $h_{1}^{r_{1}} \cdot h_{2}^{r_{2}} \cdot h_{3}^{r_{3}}$. $\ldots \cdot h_{n}^{r_{n}}$ (where, $r_{1}, r_{2}, r_{3} \ldots$ are the exponents of the primary dimensions, while $n$ is the number of the involved primary dimensions). A variable $H_{j}$ has the dimension $\left[H_{j}\right]=\varphi_{j} \cdot h_{1}^{r_{1 j}} \cdot h_{2}^{r_{2 j}} \cdot h_{3}^{r_{3 j}} \cdots$, where $\varphi_{j}$ is a coefficient.

The author of works $[31,32]$ indicates the following steps for analysis, which were presented in [33]:

- the dimensional matrix $(D M)$ is defined; it consists of the exponents of all involved dimensions $h_{i}$ that describe all independent variables $H_{k}$ and the dependent one. In the case of four variables, among one is dependent (for instance $H_{1}$ ), the dimensional relations are:

$$
H_{1}=h_{1}^{\alpha_{1}} \cdot h_{2}^{\beta_{1}} \cdot h_{3}^{\gamma_{1}} \cdot h_{4}^{\delta_{1}} ; H_{2}=h_{1}^{\alpha_{2}} \cdot h_{2}^{\beta_{2}} \cdot h_{3}^{\gamma_{2}} \cdot h_{4}^{\delta_{2}} ; H_{3}=h_{1}^{\alpha_{3}} \cdot h_{2}^{\beta_{3}} \cdot h_{3}^{\gamma_{3}} \cdot h_{4}^{\delta_{3}} ; H_{4}=h_{1}^{\alpha_{4}} \cdot h_{2}^{\beta_{4}} \cdot h_{3}^{\gamma_{4}} \cdot h_{4}^{\delta_{4}} \cdot
$$

The dimensional matrix contains the exponents of these dimensions and is indicated in rel. (6):

$\begin{array}{ccccc} & H_{1} & H_{2} & H_{3} & H_{4} \\ h_{1} & \alpha_{1} & \alpha_{2} & \alpha_{3} & \alpha_{4} \\ h_{2} & \beta_{1} & \beta_{2} & \beta_{3} & \beta_{4} \\ h_{3} & \gamma_{1} & \gamma_{2} & \gamma_{3} & \gamma_{4} \\ h_{4} & \delta_{1} & \delta_{2} & \delta_{3} & \delta_{4}\end{array}$

Matrix $M$, associated with the dimensional matrix, is:

$$
M=\left[\begin{array}{llll}
\alpha_{1} & \alpha_{2} & \alpha_{3} & \alpha_{4} \\
\beta_{1} & \beta_{2} & \beta_{3} & \beta_{4} \\
\gamma_{1} & \gamma_{2} & \gamma_{3} & \gamma_{4} \\
\delta_{1} & \delta_{2} & \delta_{3} & \delta_{4}
\end{array}\right]
$$


In the general case, there are $N_{\mathrm{V}}$ total variables and $N_{\mathrm{d}}$ primary dimensions that define both the dimensional matrix and the associated one, as a matrix consisting of $N_{\mathrm{d}}$ lines and $N_{\mathrm{V}}$ columns.

- $\quad$ it is to find the quadratic submatrix $A$, starting with the upper right elements of matrix $M$, which has the highest rank, $r$ and which will also be the rank of the dimensional matrix $R_{D M}=r$. For this purpose, some rows (dimensions that cannot be selected arbitrarily, but will result from the model law) and columns (dependent variables) are eliminated from matrix $M$, and those independent variables are set that have the exponents of the dimensions included in matrix $A$. Matrix $A$ must not be singular $(\operatorname{det}|A| \neq 0)$, and the rows contain the exponents of the primary dimensions of the remaining independent variables. The model law can comprise one or more correlations among independent and dependent variables, as will later be indicated.

- the remaining rows of matrix $M$ represent the reduced dimensional matrix $M_{1}$. They contain the primary dimensions (i.e., the dimensions that can be arbitrarily selected). The columns of matrix $M_{1}$, which are not included in matrix $A$, represent matrix $B$.

- the dimensional set is defined; it comprises the reduced dimensional matrix $(B+A)$, matrix $C=-\left(A^{-1} \cdot B\right)^{T}$ and the unit matrix of order $\mathrm{n}, D \equiv I_{n \times n}$, as indicated by (8) and (9) $[31,32,34]$.

\begin{tabular}{|c|c|c|c|}
\hline \multirow{6}{*}{$\begin{array}{l}\text { The rows correspond to the } \\
\text { remaining primary dimensions } \\
k=N_{d} \text { after defining matrix } A\end{array}$} & 1. & \multirow{6}{*}{$B$} & \multirow{6}{*}{$A$} \\
\hline & 2. & & \\
\hline & 3. & & \\
\hline & 4. & & \\
\hline & $\ldots$ & & \\
\hline & $k$. & & \\
\hline \multirow{7}{*}{$\begin{array}{l}\text { The rows correspond to } n \text { columns } \\
\text { (dependent variables) that had } \\
\text { matrix } B \text {; the number of the rows is } \\
\text { the same as that of the } \pi_{j} \text {, resulting } \\
\text { in dimensionless quantities }\end{array}$} & 1. & \multirow{7}{*}{$D \equiv I_{n \times n}$} & \multirow{7}{*}{$C=-\left(A^{-1} \cdot B\right)^{T}$} \\
\hline & 2. & & \\
\hline & 3. & & \\
\hline & 4. & & \\
\hline & $\ldots$ & & \\
\hline & $\ldots$ & & \\
\hline & $n$ & & \\
\hline
\end{tabular}

$$
D \equiv I_{n \times n}
$$

It should be mentioned that matrix $C$ is obtained from the relation:

$$
C=-\left(A^{-1} \cdot B\right)^{T}
$$

Relation (9) is valid if the set of new variables contains only $\pi_{j}$ dimensionless quantitates and matrix $D$ is a unit matrix.

- $\quad$ the rows $j=1,2, \ldots, n$ of matrixes $D$ and $C$ define all $\pi_{j}$ dimensionless quantitates. Thus, row $j$ of the common matrix $(D$ and $C$ ) contains the exponents that are involved in defining $\pi_{j}$, which is the product between a dependent variable (from matrix $B$, having the exponent 1 ) and all involved independent variables (from matrix $A$, having the exponents from the row $j$ of matrix $C$ ). In order to find the model law, the expressions of all $\pi_{j}$ dimensionless variables are equal to one. In all products of matrix $D$ there is only one dependent variable with exponent 1 , while in those of matrix $C$ there are all independent variables with the exponents obtained from relation (9).

As mentioned before, in the matrices A, B and C the exponents $\left(h_{1}, h_{2}, \ldots, h_{m}\right)$ of the basic dimensions involved intervene, which helps us to describe the set of variables involved $\left(H_{1}, H_{2}, H_{3}, \ldots, H_{n}\right)$, and in matrix $\mathrm{D}$ (which is a unit matrix) these unit values will also represent exponents of dependent variables.

The illustration of how to obtain the elements of the model law is given in Figure 1: 


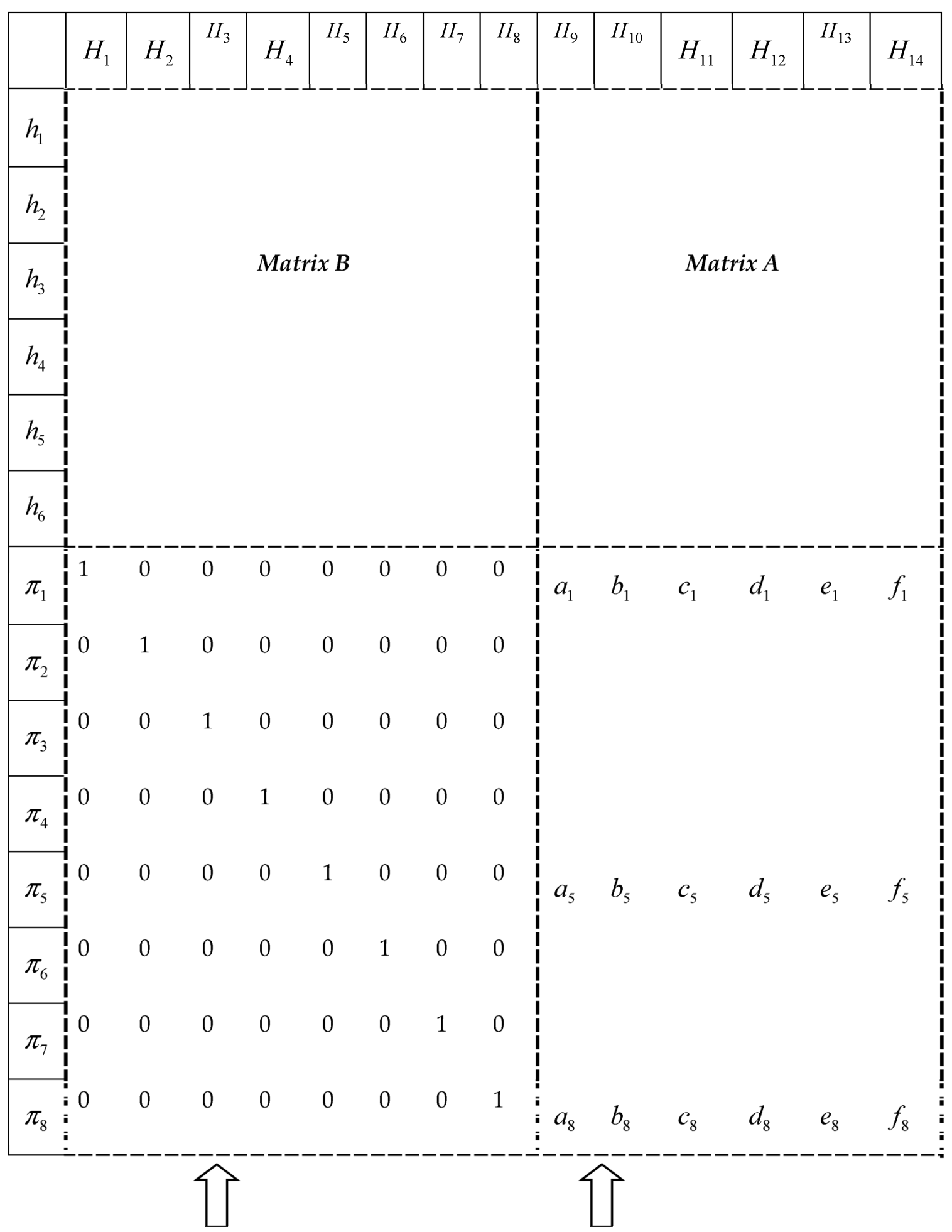

Matrix D

Matrix C

Figure 1. The illustration of how to obtain the elements of the model law.

If considering, for example, the dimensionless variable $\pi_{5}$, on its line there are the exponents of all involved independent variables $\left(H_{9}, \ldots, H_{14}\right)$, the exponents of the independent variables $\left(a_{5}, \ldots, f_{5}\right)$, as well as the exponent of the dependent variable 
$\left(H_{5}\right)$, which is 1 , being positioned on the main diagonal of matrix $D$. Consequently, $\pi_{5}$ can be written as:

$$
\pi_{5}=\left(H_{5}\right)^{1} \cdot\left(H_{9}\right)^{a_{5}} \cdot\left(H_{10}\right)^{b_{5}} \cdot\left(H_{11}\right)^{c_{5}} \cdot\left(H_{12}\right)^{d_{5}} \cdot\left(H_{13}\right)^{e_{5}} \cdot\left(H_{14}\right)^{f_{5}},
$$

As shown before, relation (10) is equal to the unit, and from this equality the dependent variable is expressed (here being $H_{5}$ ), i.e.,

$$
\begin{gathered}
\pi_{5}=\left(H_{5}\right)^{1} \cdot\left(H_{9}\right)^{a_{5}} \cdot\left(H_{10}\right)^{b_{5}} \cdot\left(H_{11}\right)^{c_{5}} \cdot\left(H_{12}\right)^{d_{5}} \cdot\left(H_{13}\right)^{e_{5}} \cdot\left(H_{14}\right)^{f_{5}}=1 \Rightarrow \\
\Rightarrow H_{5}=\frac{1}{\left(H_{9}\right)^{a_{5}} \cdot\left(H_{10}\right)^{b_{5}} \cdot\left(H_{11}\right)^{c_{5}} \cdot\left(H_{12}\right)^{d_{5}} \cdot\left(H_{13}\right)^{e_{5}} \cdot\left(H_{14}\right)^{f_{5}}}
\end{gathered}
$$

Then, the involved variables $\left(H_{5}, H_{9}, \ldots, H_{14}\right)$ are replaced by the corresponding scale factors $\left(S_{H_{n}}\right)$, and finally, the desired expression of the fifth element of the model law is obtained.

Obviously, some of the exponents involved being negative, the relationship obtained will be in the form of an ordinary fraction, where both the numerator and the denominator will have expressions of scale factors at certain powers.

Some observations can be formulated as:

- $\quad$ in this case, the model law will consist of eight elements, since eight dimensional variables resulted from the calculations $\left(\pi_{1}, \ldots, \pi_{8}\right)$;

- $\quad$ at the same time, this law includes the complete set of dimensionless variables $\pi_{k}$ involved in the description of the analyzed physical phenomenon, and the way to obtain these dimensionless variables is the easiest and safest, which cannot be achieved with the rest of the methods mentioned above;

- for simplification, $\pi_{j}$ variables can be further grouped.

- $\quad$ Some conclusions can be drawn from the previous $M D A$ analysis, namely:

- $\quad$ as compared to $C D A$, the relations of the Model obtained from $M D A$ are correlations among variables that are involved in the phenomenon, which actually represent connections between the scale factors of the involved variables. They must not be compared with the physical relations that describe the phenomenon

- $\quad$ if opting for the case in which the set of new variables comprises only $\pi_{j}$ dimensionless variables and matrix $D$ is quadratic, but not a unit matrix, then matrix $C$ is calculated from relation (10) [31,32]:

$$
C=-D \cdot\left(A^{-1} \cdot B\right)^{T}
$$

the final expressions of the $\pi_{j}$ variables do not change;

- the order of introducing the dependent variables in matrix $B$ and independent variables in matrix $A$ and thus, their positioning in the reduced dimensional matrix $(B-A)$ and dimensional set $(B-A-D-C)$, respectively, does not influence the $\pi_{j}$ relations and model law;

- $\quad$ the new approach proposed by $M D A$ has the following advantages [31,32]:

- all parameters that might have an influence upon the phenomenon are considered (total variables of the dimensional set). More information in defining the relevant variables increases the degree of freedom in selecting the properties of the model, and thus a more reliable description of the prototype is possible. Later, based on a careful analysis, the variables that have an insignificant influence can be excluded.

- the $\pi_{j}$ variables can be easily and unitarily determined, which is impossible if $C D A$ or the theory of similarity are used. It means that the dimensional set defined by Equation (8) represents the complete set of $\pi_{j}$ dimensionless products of variables $H_{m}, \quad m=N_{V}$ :

- the calculations required for the arbitrary grouping and analysis used by the two previously mentioned methods, in order to obtain the $\pi_{j}$ groups, are 
eliminated. They require a thorough knowledge of the phenomenon, thus making $C D A$ difficult and inaccessible to many researchers;

○

in contrast, $M D A$ considers the variables that might influence the phenomenon without requiring a thorough knowledge of the phenomenon and the governing relations;

in order to determine the model law that consists of the constitutive expressions of the $\pi_{j}$ variables, each $\pi_{j}$ variable is equal to one and each variable $\eta$ is replaced by the corresponding scale factor $S_{\eta}$. From these expressions, the scale factors of the dependent variables are determined as function of the independent ones, thus obtaining the components of the model law.

\section{Application of $M D A$ to the Heat Transfer in a Circular Bar. Case Study}

\subsection{General Approach}

A metallic (steel) bar with a circular section is considered, being related to the reference system $x$ Grt (Figure 2).

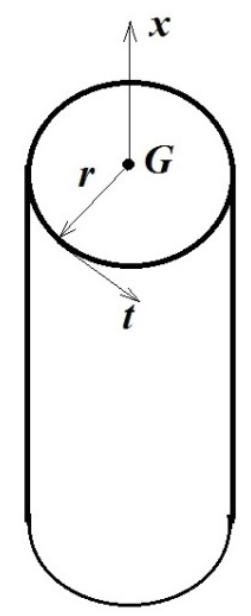

Figure 2. Bar with circular section.

Generally, the set of variables that govern the transient heat transfer in a bar with circular section that can be further analyzed in terms of dimensions are indicated in Table 1:

Table 1. The set of variables that govern the heat transient transfer in a beam with circular section.

\begin{tabular}{|c|c|c|}
\hline \multicolumn{3}{|c|}{ Variable } \\
\hline Name & Symbol/Formula & Dimension \\
\hline Heat * & Q & $J=N \cdot m=\frac{\mathrm{kg} \cdot \mathrm{m}_{x}}{\mathrm{~s}^{2}} \cdot m_{x}=\frac{\mathrm{kg} \cdot \mathrm{m}_{x}^{2}}{\mathrm{~s}^{2}}$ \\
\hline Heat rate & $\dot{Q}=\frac{d Q}{d \tau}$ & $W=\frac{J}{s}=\frac{k g \cdot m_{x}^{2}}{s^{3}}$ \\
\hline Time & $\tau, \Delta \tau$ & $s$ \\
\hline $\begin{array}{c}\text { Density of material } \\
\text { (steel, air, paint/insulating material) }\end{array}$ & $\rho$ & $\frac{k g}{m^{3}}=\frac{k g}{m_{x} \cdot m_{r}^{2}}$ \\
\hline $\begin{array}{l}\text { Constant-pressure } \\
\text { specific heat of air }\end{array}$ & $c_{p}=\frac{1}{m} \cdot \frac{d Q}{d t}$ & $\frac{1}{k g} \cdot \frac{J}{{ }^{0} \mathrm{C}}=\frac{1}{\mathrm{~kg}} \cdot \frac{\mathrm{kg} \cdot \mathrm{m}_{x}^{2}}{\mathrm{~s}^{2} \cdot{ }^{0} \mathrm{C}}=\frac{m_{x}^{2}}{\mathrm{~s}^{2} \cdot{ }^{\circ} \mathrm{C}}$ \\
\hline Specific heat capacity(steel, air) & $C=\frac{d Q}{d T}$ & $\frac{J}{{ }^{0} \mathrm{C}}=\frac{\mathrm{kg} \cdot \mathrm{m}_{x}^{2}}{\mathrm{~s}^{2} .0^{0} \mathrm{C}}$ \\
\hline
\end{tabular}


Table 1. Cont.

\begin{tabular}{|c|c|c|}
\hline \multicolumn{3}{|c|}{ Variable } \\
\hline Name & Symbol/Formula & Dimension \\
\hline \multirow{2}{*}{$\begin{array}{l}\text { Thermal conductivity(steel, paint), } \\
\text { along directions }\end{array}$} & $\lambda_{x}($ for steel $)$ & $\begin{array}{c}\frac{W}{m_{x}{ }^{0} \mathrm{C}}=\frac{J}{s} \cdot \frac{1}{m_{x} \cdot{ }^{0} \mathrm{C}}= \\
\frac{1}{s} \cdot \frac{k g \cdot m_{x}^{2}}{s^{2}} \cdot \frac{1}{m_{x} \cdot{ }^{0} \mathrm{C}}=\frac{k \cdot m_{x}}{s^{3} \cdot{ }^{0} \mathrm{C}}\end{array}$ \\
\hline & $\lambda_{r}$ (for steel or paint coat) & $\begin{array}{c}\frac{W}{m_{r} \cdot{ }^{0} \mathrm{C}}=\frac{J}{s} \cdot \frac{1}{m_{r} \cdot{ }^{0} \mathrm{C}}= \\
\frac{1}{s} \cdot \frac{\mathrm{kg} \cdot \mathrm{m}_{x}^{2}}{\mathrm{~s}^{2}} \cdot \frac{1}{m_{r} \cdot{ }^{0} \mathrm{C}}=\frac{\mathrm{kg} \cdot \mathrm{m}_{x}^{2}}{\mathrm{~s}^{3} \cdot \mathrm{m}_{r} \cdot{ }^{\circ} \mathrm{C}}\end{array}$ \\
\hline \multirow{2}{*}{$\begin{array}{l}\text { Thermal diffusivity of air, along } \\
\text { directions }\end{array}$} & $a_{x}=\frac{\lambda_{x}}{\rho \cdot c_{p}}=\frac{1}{\rho} \cdot \frac{1}{c_{p}} \cdot \lambda_{x}$ & $\begin{array}{c}a_{x}=\frac{\lambda_{x}}{\rho \cdot c_{p}}= \\
\frac{1}{\rho} \cdot \frac{1}{c_{p}} \cdot \lambda_{x}\left(\frac{m_{x} \cdot m_{r}^{2}}{k g} \cdot \frac{s^{2} \cdot 0 \mathrm{C}}{m_{x}^{2}} \cdot \frac{k g \cdot m_{x}}{\mathrm{~s}^{3} \cdot 0^{\circ} \mathrm{C}}=\frac{m_{r}^{2}}{\mathrm{~s}}\right)\end{array}$ \\
\hline & $a_{r}=\frac{\lambda_{r}}{\rho \cdot c_{p}}=\frac{1}{\rho} \cdot \frac{1}{c_{p}} \cdot \lambda_{r}$ & $\frac{m_{x} \cdot m_{r}^{2}}{k g} \cdot \frac{s^{2} \cdot{ }^{0} \mathrm{C}}{m_{x}^{2}} \cdot \frac{k g \cdot m_{x}^{2}}{s^{3} \cdot m_{r} \cdot{ }^{0} \mathrm{C}}=\frac{m_{x} \cdot m_{r}}{s}$ \\
\hline \multirow{2}{*}{ Dynamic viscosity of air ** } & $\eta=\tau_{0 x} \cdot \frac{1}{\nabla w_{0}}=\frac{F_{0 x}}{A} \cdot \frac{1}{\nabla w_{0}}$ & $\frac{k g}{s^{2} \cdot m_{t}} \cdot \frac{1}{1 / s}=\frac{k g}{s \cdot m_{t}}$ \\
\hline & $\eta_{r}=\frac{\tau_{0 r}}{\nabla w_{0}}=\frac{F_{0 r}}{A} \cdot \frac{1}{\nabla w_{0}}$ & $\frac{k g}{s^{2} \cdot m_{r}} \cdot \frac{1}{1 / s}=\frac{k g}{s \cdot m_{r}}$ \\
\hline \multirow{2}{*}{$\begin{array}{l}\text { Kinematic } \\
\text { viscosity } \\
\text { of air }\end{array}$} & $v_{x}=\frac{\eta_{x}}{\rho}=\frac{1}{\rho} \cdot \eta_{x}$ & $\frac{m_{x} \cdot m_{r}^{2}}{k g} \cdot \frac{k g}{s \cdot m_{t}}=\frac{m_{x} \cdot m_{r}^{2}}{s \cdot m_{t}}$ \\
\hline & $v_{y}=\frac{\eta_{r}}{\rho}=\frac{1}{\rho} \cdot \eta_{r}$ & $\frac{m_{x} \cdot m_{r}^{2}}{k g} \cdot \frac{k g}{s \cdot m_{r}}=\frac{m_{x} \cdot m_{r}}{s}$ \\
\hline \multirow{2}{*}{$\begin{array}{l}\text { Prandtl number } \\
\text { of air, along directions }\end{array}$} & $\operatorname{Pr}_{x}=\frac{v_{x}}{a_{x}}=v_{x} \cdot \frac{1}{a_{x}}$ & $\frac{m_{x} \cdot m_{r}^{2}}{s \cdot m_{t}} \cdot \frac{s}{m_{r}^{2}}=\frac{m_{x}}{m_{t}}$ \\
\hline & $\operatorname{Pr}_{r}=\frac{v_{r}}{a_{r}} * * *$ & $\frac{m_{x} \cdot m_{r}}{s} \cdot \frac{s}{m_{x} \cdot m_{r}}=1=m_{x}^{0} \cdot m_{r}^{0} \cdot s^{0}$ \\
\hline \multirow{2}{*}{$\begin{array}{l}\text { Convection heat transfer coefficient } \\
\text { along directions }\end{array}$} & $\alpha_{n x}$ & $\begin{array}{c}\frac{W}{m^{2.0} \mathrm{C}}=\frac{J}{s} \cdot \frac{1}{m^{2.0} \mathrm{C}}=\frac{\mathrm{kg} \cdot \mathrm{m}_{x}^{2}}{\mathrm{~s}^{3}} \cdot \frac{1}{\mathrm{~m}_{r}^{2} \cdot{ }^{0} \mathrm{C}}= \\
\frac{\mathrm{kg} \cdot \mathrm{m}_{x}^{2}}{\mathrm{~s}^{3} \cdot \mathrm{m}_{r}^{2} \cdot{ }^{\circ} \mathrm{C}}\end{array}$ \\
\hline & $\begin{array}{l}\alpha_{n r} \text { (when the beam is protected (insulated) by a } \\
\left.\text { paint coat, then: } \alpha_{n f}=\alpha_{n r}\right)\end{array}$ & $\begin{array}{c}\frac{W}{m^{2} \cdot{ }^{0} \mathrm{C}}=\frac{I}{\mathrm{~s}} \cdot \frac{1}{\mathrm{~m}^{2} \cdot \mathrm{C}^{\circ} \mathrm{C}}=\frac{\mathrm{kg} \cdot \mathrm{m}_{x}^{2}}{\mathrm{~s}^{3}} \cdot \frac{1}{\mathrm{~m}_{x} \cdot \mathrm{m}_{t}{ }^{0} \mathrm{C}}= \\
\frac{\mathrm{kg} \cdot \mathrm{m}_{x}}{\mathrm{~s}^{3} \cdot \mathrm{m}_{t} \cdot{ }^{\circ} \mathrm{C}}\end{array}$ \\
\hline $\begin{array}{l}\text { Thickness of the paint coat along } \\
\text { the radial direction }\end{array}$ & $d_{r}=\delta_{r}$ & $m_{r}$ \\
\hline Beam volume & $V$ & $m^{3}=m_{x} \cdot m_{r}^{2}$ \\
\hline Area of the beam cross section & $A_{t r}$ & $m_{r}^{2}$ \\
\hline Lateral area & $A_{\text {lat }}$ & $m_{x} \cdot m_{t}$ \\
\hline Beam dimensions & $L_{x}, L_{r}, L_{t}$ & $m_{x}, m_{r}, m_{t}$ \\
\hline Shape factor of the cross-section & $\varsigma=\frac{A_{\text {lat }}}{V}=\frac{P}{A_{t r}} ; P$ is the cross-section perimeter & $\frac{m_{t}}{m_{r}^{2}}$ \\
\hline Gravitational acceleration & $g$ & $\frac{m}{s^{2}}=\frac{m_{x}}{s^{2}}$ \\
\hline Temperature variation & $\Delta T(K)$ or $\Delta t\left({ }^{\circ} \mathrm{C}\right)$ & $\Delta T(K)$ or $\Delta t\left({ }^{\circ} \mathrm{C}\right)$ \\
\hline $\begin{array}{l}\text { Coefficient of volume expansion of } \\
\text { steel or of fluid/air }\end{array}$ & $\beta$ & $\frac{1}{{ }^{\circ} \mathrm{C}}$ \\
\hline \multirow{2}{*}{ Nusselt number, along directions } & $\begin{array}{l}N u_{x}=\frac{\alpha_{x} \cdot l_{x}}{\lambda_{f, x}}=\alpha_{x} \cdot l_{x} \cdot \frac{1}{\lambda_{f, x}} \\
l_{x}\left(m_{x}\right) \text {-characteristic length }\end{array}$ & $\frac{\mathrm{kg} \cdot \mathrm{m}_{x}^{2}}{\mathrm{~s}^{3} \cdot \mathrm{m}_{r}^{2} \cdot{ }^{2} \mathrm{C}} \cdot m_{x} \cdot \frac{\mathrm{s}^{3} \cdot{ }^{0} \mathrm{C}}{\mathrm{kg} \cdot \mathrm{m}_{x}}=\frac{m_{x}^{2}}{m_{r}^{2}}$ \\
\hline & $\begin{array}{l}N u_{r}=\frac{\alpha_{r} \cdot l_{r}}{\lambda_{f, r}}=\alpha_{r} \cdot l_{r} \cdot \frac{1}{\lambda_{f, r}} \\
l_{r}\left(m_{r}\right) \text {-characteristic length }\end{array}$ & $\frac{\mathrm{kg} \cdot \mathrm{m}_{x}}{\mathrm{~s}^{3} \cdot \mathrm{m}_{t} \cdot{ }^{0} \mathrm{C}} \cdot m_{r} \cdot \frac{\mathrm{s}^{3} \cdot m_{r} \cdot{ }^{0} \mathrm{C}}{\mathrm{kg} \cdot m_{x}^{2}}=\frac{m_{r}^{2}}{m_{t} \cdot m_{x}}$ \\
\hline Reynolds number, along directions & $\begin{array}{c}\operatorname{Re}_{x}=\frac{w_{0, x} \cdot l_{x}}{v_{x}}=w_{0, x} \cdot l_{x} \cdot \frac{1}{v_{x}} ; w_{0}\left(\frac{m}{s}\right) \text { is the fluid } \\
\text { velocity }\end{array}$ & $\frac{m_{x}}{s} \cdot m_{x} \cdot \frac{s \cdot m_{t}}{m_{x} \cdot m_{r}^{2}}=\frac{m_{x} \cdot m_{t}}{m_{r}^{2}}$ \\
\hline
\end{tabular}


Table 1. Cont.

\begin{tabular}{|c|c|c|}
\hline \multicolumn{3}{|c|}{ Variable } \\
\hline Name & Symbol/Formula & Dimension \\
\hline \multirow{2}{*}{ Péclet number, along directions } & $\begin{array}{c}\operatorname{Re}_{r}=\frac{w_{0, r} \cdot l_{r}}{v_{r}}=w_{0, r} \cdot l_{r} \cdot \frac{1}{v_{r}} \\
P e_{x}=\operatorname{Re}_{x} \cdot \operatorname{Pr}_{x}\end{array}$ & $\begin{array}{c}\frac{m_{r}}{s} \cdot m_{r} \cdot \frac{s}{m_{x} \cdot m_{r}}=\frac{m_{r}}{m_{x}} \\
\frac{m_{x} \cdot m_{t}}{m_{r}^{2}} \cdot \frac{m_{x}}{m_{t}}=\frac{m_{x}^{2}}{m_{r}^{2}}\end{array}$ \\
\hline & $P e_{r}=\frac{m_{r}}{m_{x}} P e_{r}=\operatorname{Re}_{r} \cdot \operatorname{Pr}_{r}$ & $\frac{m_{r}}{m_{x}} \cdot 1=\frac{m_{r}}{m_{x}}$ \\
\hline Grashof number & $G r_{x}=\frac{g \cdot \beta \cdot \Delta t \cdot l_{\zeta}^{3}}{v_{\zeta}^{2}}=g \cdot \beta \cdot \Delta t \cdot l_{x}^{3} \cdot \frac{1}{v_{x}^{2}}$ & $\frac{m_{x}}{s^{2}} \cdot \frac{1}{{ }^{0} \mathrm{C}} \cdot{ }^{0} \mathrm{C} \cdot m_{x}^{3} \cdot \frac{s^{2} \cdot m_{t}^{2}}{m_{x}^{2} \cdot m_{r}^{4}}=\frac{m_{x}^{2} \cdot m_{t}^{2}}{m_{r}^{4}}$ \\
\hline \multirow{2}{*}{ Stanton number, along directions } & $S t_{x}=\frac{N u_{x}}{P e_{x}}=N u_{x} \cdot \frac{1}{P e_{x}} * * *$ & $\frac{m_{x}^{2}}{m_{z} \cdot m_{y}} \cdot \frac{m_{z} \cdot m_{y}}{m_{x}^{2}}=1$ \\
\hline & $S t_{r}=\frac{N u_{r}}{P e_{r}}=N u_{r} \cdot \frac{1}{P e_{r}}$ & $\frac{m_{r}^{2}}{m_{x} \cdot m_{t}} \cdot \frac{m_{x}}{m_{r}}=\frac{m_{r}}{m_{t}}$ \\
\hline \multirow{2}{*}{ Fourier number, along directions } & $F o_{x}=\frac{a_{x} \cdot \tau}{l_{x}^{2}}=\frac{a_{x} \cdot \Delta \tau}{l_{x}^{2}}=a_{x} \cdot \Delta \tau \cdot \frac{1}{l_{x}^{2}}$ & $\frac{m_{r}^{2}}{s} \cdot s \cdot \frac{1}{m_{x}^{2}}=\frac{m_{r}^{2}}{m_{x}^{2}}$ \\
\hline & $F o_{r}=\frac{a_{r} \cdot \tau}{l_{r}^{2}}=\frac{a_{r} \cdot \Delta \tau}{l_{r}^{2}}=a_{r} \cdot \Delta \tau \cdot \frac{1}{l_{r}^{2}}$ & $\frac{m_{x} \cdot m_{r}}{s} \cdot s \cdot \frac{1}{m_{r}^{2}}=\frac{m_{x}}{m_{r}}$ \\
\hline \multirow{2}{*}{ Biot number, along directions } & $B i_{x}=\frac{\alpha_{x} \cdot l_{x}}{\lambda_{s, x}}=\alpha_{x} \cdot l_{x} \cdot \frac{1}{\lambda_{s, x}}$ & $\frac{\mathrm{kg} \cdot \mathrm{m}_{x}^{2}}{\mathrm{~s}^{3} \cdot \mathrm{m}_{r}^{2} \cdot{ }^{0} \mathrm{C}} \cdot m_{x} \cdot \frac{\mathrm{s}^{3} \cdot{ }^{0} \mathrm{C}}{\mathrm{kg} \cdot \mathrm{m}_{x}}=\frac{m_{x}^{2}}{m_{r}^{2}}$ \\
\hline & $B i_{r}=\frac{\alpha_{r} \cdot l_{r}}{\lambda_{s, r}}=\alpha_{r} \cdot l_{r} \cdot \frac{1}{\lambda_{s, r}}$ & $\frac{\mathrm{kg} \cdot m_{x}}{\mathrm{~s}^{3} \cdot m_{t} \cdot{ }^{0} \mathrm{C}} \cdot m_{r} \cdot \frac{\mathrm{s}^{3} \cdot m_{r} \cdot{ }^{0} \mathrm{C}}{\mathrm{kg} \cdot \mathrm{m}_{x}^{2}}=\frac{m_{r}^{2}}{m_{t} \cdot m_{x}}$ \\
\hline
\end{tabular}

${ }^{*}$ Heat is numerically equal to the dimension of work; the work is conventionally considered a product between a force having the direction along the bar, $F_{x}\left(N_{x}=\frac{k g \cdot m_{x}}{c^{2}}\right)$ and the displacement along the same direction $x\left(m_{x}\right) .{ }^{* *}$ where the shear stress $\tau_{0}$ has one of the directions, $x$ or $r$, of the system $x G r t$, the applied force is $F_{0}$, while the surface $A$ where it occurs is in a plane that contains the direction of the shear stress; the velocity $w_{0}$ is normal to the plane where the shear stress is developed; $\nabla w_{0}$ represents its gradient. ${ }^{* * *}$ this is not suitable for dimensional analysis (Therefore, it cannot be used in the dimensional analysis).

Having the dimensions of the variables involved in the transient heat transfer, the MDA was applied as described by Szirtes in [31,32]. Additionally, for acquiring the simplest relations of the model law, according to [31,32], the dimensions were duplicated (in this case, the lengths were duplicated). This will contribute to the reduction in the number of $\pi_{j}, j=1, \ldots, n$ dimensionless variables, once the dimensions of the variables involved increase. Thus, the reduced number of expressions of the Model Law will be obtained.

According to the principles mentioned in [31,32], the following two sets of independent variables were selected:

- $\quad$ for the first version (I): $\left[\left(Q, L_{t}, \Delta t, \tau, \lambda_{x \text { steel }}, \zeta\right]\right.$;

- $\quad$ for the second version (II): $\left[\dot{Q}, L_{t}, \Delta t, \tau, \lambda_{x \text { steel }}, \zeta\right]$,

which are directly connected with the measurements that were performed and whose magnitude can be controlled during experiments carried out on the model.

These sets are included in matrix $A$; the other quantities, representing dependent variables, form matrix $B$.

It should be noted that the variables contained in matrix A are freely chosen, both for the prototype and for the model. The advantage of choosing these two sets of independent variables lies, inter alia, in the following:

- heating regimes can be chosen independently for prototype and model by:

$\circ \quad$ accepting convenient and well-determined values for the amount of heat introduced into the system $(Q$ or $\dot{Q})$;

$\circ \quad$ setting final temperatures compared to initial ones $(\Delta t)$,

$\circ \quad$ defining/accepting individual heating times $(\tau)$ of the prototype and the model;

- length scales can also be chosen independently (expressed here as $L_{t}$, which can be extended to the rest of the dimensions, but it is not mandatory, because the rest of the dimensions are also included in matrix $B$, which represents a significant reserve for generalizing the model to the prototype); 
- the factors $\varsigma$ (shape factor) of the cross sections can be chosen independently in the prototype and for the model, respectively;

- one can define the materials of the prototype and the model by $\lambda_{x}$, which do not necessarily have to be for both steel, which is also very important for the most favorable experiments (costs, manufacturing time, test times etc).

In the following, the obtained results for these two variants are analyzed.

\subsection{First Case Study}

Version I is based on the above-described protocol of the MDA and the following quantities were successively obtained:

- the dependent variables that define the heat transfer in the beam that is not coated with intumescent paint, based on experimental research: $\dot{Q}, A_{t r}, A_{\text {lat }}, r_{c y l}, L_{x}, L_{r}$

- the dependent variables that are useful for theoretical analyses:

$c_{p \text { air }}, C_{\text {air }}, C_{\text {steel }}, a_{x}$ air $, a_{r \text { air }}, \rho_{\text {air }}, \rho_{\text {steel }}, \lambda_{r \text { steel }}, v_{x \text { air }}, v_{r \text { air }}, \alpha_{n x \text { steel }}, \alpha_{n r \text { steel }}, \eta_{x \text { air }}, \eta_{r \text { air }}, \beta_{\text {air } / \text { steel }}$

- the dependent variables that are useful for setting convection heat transfer correlations between dimensionless numbers (similarity criteria) Crit01, Crit02, Crit03, $\operatorname{Pr}_{x}$, $G r_{x}$ air,$F o_{x}$ air $F o_{r}$ air $, \operatorname{Re}_{r \text { air }}, S t_{r \text { air }}$ where the mentioned dimensionless numbers are:

$$
\begin{gathered}
\text { Crit } 01=\operatorname{Re}_{r}=P e_{r}=\frac{m_{x}}{m_{r}} ; \text { Crit } 02=N u_{x}=P e_{x}=B i_{x}=\frac{m_{x}^{2}}{m_{r}^{2}} ; \\
\text { Crit } 03=N u_{r}=B i_{r}=\frac{m_{r}^{2}}{m_{x} \cdot m_{t}},
\end{gathered}
$$

- $\quad$ the properties of the paint layer: $\rho_{\text {paint }}, \lambda_{x \text { paint }}, \lambda_{r \text { paint }}, \alpha_{n r}$ paint,$\delta_{r \text { paint }}$

The components of the reduced dimensional matrix $(B+A)$ are indicated in Tables $2-6$, where, as mentioned before, these elements represent exactly the exponents of the dimensions involved in defining those variables.

Table 2. Matrix A, comprising independent variables.

\begin{tabular}{ccccccc}
\hline Dimensions & $\boldsymbol{Q}$ & $\boldsymbol{L}_{\boldsymbol{t}}$ & $\boldsymbol{\Delta}$ & $\boldsymbol{\tau}$ & $\lambda_{\text {x steel }}$ & $\boldsymbol{\zeta}=\boldsymbol{P} / \boldsymbol{A}$ \\
\hline$m_{x}$ & 2 & 0 & 0 & 0 & 1 & 0 \\
\hline$m_{r}$ & 0 & 0 & 0 & 0 & 0 & -2 \\
\hline$m_{t}$ & 0 & 1 & 0 & 0 & 0 & 1 \\
\hline $\mathrm{kg}$ & 1 & 0 & 0 & 0 & 1 & 0 \\
\hline $\mathrm{s}$ & -2 & 0 & 0 & 1 & -3 & 0 \\
\hline${ }^{\circ} \mathrm{C}$ & 0 & 0 & 1 & 0 & -1 & 0 \\
\hline
\end{tabular}

Table 3. The quantities required by experiments (part of matrix B).

\begin{tabular}{ccccccc}
\hline Dimensions & $\dot{Q}$ & $A_{t r}$ & $A_{\text {lat }}$ & $\boldsymbol{r}_{c y l}$ & $\boldsymbol{L}_{\boldsymbol{x}}$ & $\boldsymbol{L}_{\boldsymbol{r}}$ \\
\hline$m_{x}$ & 2 & 0 & 1 & 0 & 1 & 0 \\
\hline$m_{r}$ & 0 & 2 & 0 & 1 & 0 & 1 \\
\hline$m_{t}$ & 0 & 0 & 1 & 0 & 0 & 0 \\
\hline $\mathrm{kg}$ & 1 & 0 & 0 & 0 & 0 & 0 \\
\hline $\mathrm{s}$ & -3 & 0 & 0 & 0 & 0 & 0 \\
\hline${ }^{\circ} \mathrm{C}$ & 0 & 0 & 0 & 0 & 0 & 0 \\
\hline
\end{tabular}


Table 4. The quantities required by the theoretic analysis (part of matrix B).

\begin{tabular}{|c|c|c|c|c|c|c|c|c|c|c|c|c|c|c|c|}
\hline Dimensions & $c_{p \text { air }}$ & $C_{a i r}$ & $C_{\text {steel }}$ & $a_{x \text { air }}$ & $a_{\text {rair }}$ & $\rho_{\text {air }}$ & $\rho_{\text {steel }}$ & $\lambda_{\text {rsteel }}$ & $v_{x a i r}$ & $v_{r a i r}$ & $\alpha_{n x \text { steel }}$ & $\alpha_{n r \text { steel }}$ & $\eta_{x \text { air }}$ & $\eta_{\text {rair }}$ & $\beta_{\text {air/steel }}$ \\
\hline$m_{x}$ & 2 & 2 & 2 & 0 & 1 & -1 & -1 & 2 & 1 & 1 & 2 & 1 & 0 & 0 & 0 \\
\hline$m_{r}$ & 0 & 0 & 0 & 2 & 1 & -2 & -2 & -1 & 2 & 1 & -2 & 0 & 0 & -1 & 0 \\
\hline$m_{t}$ & 0 & 0 & 0 & 0 & 0 & 0 & 0 & 0 & -1 & 0 & 0 & -1 & -1 & 0 & 0 \\
\hline $\mathrm{kg}$ & 0 & 1 & 1 & 0 & 0 & 1 & 1 & 1 & 0 & 0 & 1 & 1 & 1 & 1 & 0 \\
\hline $\mathrm{s}$ & -2 & -2 & -2 & -1 & -1 & 0 & 0 & -3 & -1 & -1 & -3 & -3 & -1 & -1 & 0 \\
\hline${ }^{\circ} \mathrm{C}$ & -1 & -1 & -1 & 0 & 0 & 0 & 0 & -1 & 0 & 0 & -1 & -1 & 0 & 0 & -1 \\
\hline
\end{tabular}

Table 5. The quantities required by the heat transfer correlations between dimensionless numbers (part of matrix B).

\begin{tabular}{|c|c|c|c|c|c|c|c|c|c|}
\hline Dimensions & Crit 01 & Crit 02 & Crit 03 & $\operatorname{Pr}_{x \text { air }}$ & $G r_{x a i r}$ & Fo $o_{x \text { air }}$ & $F o_{\text {rair }}$ & $\mathbf{R e}_{x \text { air }}$ & $S t_{\text {r air }}$ \\
\hline$m_{x}$ & 1 & 2 & -1 & 0 & -1 & -2 & 1 & -1 & 0 \\
\hline$m_{r}$ & -1 & -2 & 2 & 0 & 1 & 2 & 0 & 0 & 1 \\
\hline$m_{t}$ & 0 & 0 & -1 & 0 & 0 & 0 & 0 & 1 & -1 \\
\hline $\mathrm{kg}$ & 0 & 0 & 0 & 0 & 0 & 0 & 0 & 0 & 0 \\
\hline $\mathrm{s}$ & 0 & 0 & 0 & 0 & 0 & 0 & -2 & 0 & 0 \\
\hline${ }^{\circ} \mathrm{C}$ & 0 & 0 & 0 & -1 & 0 & 0 & 0 & 0 & 0 \\
\hline
\end{tabular}

Table 6. The properties of the intumescent paint (part of matrix B).

\begin{tabular}{cccccc}
\hline & $\rho_{\text {paint }}$ & $\lambda_{\text {x paint }}$ & $\lambda_{\text {r paint }}$ & $\alpha_{\text {nr paint }}$ & $\delta_{r \text { paint }}$ \\
\hline$m_{x}$ & -1 & 1 & 2 & -1 & 0 \\
\hline$m_{r}$ & -2 & 0 & 0 & -1 & 0 \\
\hline$m_{t}$ & 0 & 0 & 1 & -3 & 0 \\
\hline $\mathrm{kg}$ & 1 & 1 & -3 & -1 & 0 \\
\hline $\mathrm{s}$ & 0 & -3 & -1 & 0 \\
\hline${ }^{\circ} \mathrm{C}$ & 0 & & &
\end{tabular}

By performing the above-mentioned calculations, the elements of the Dimensional Set were finally obtained, from where all dimensionless $\pi_{j}$ expressions were extracted as corresponding lines of the Dimensional Set. In the following, this step-by-step procedure is presented just for the first expression of the model law (related to the dimensionless variable) and for the rest, only the final expressions of the model law are indicated. Thus, the following were obtained:

(a) From experiments on uncoated structures (prototype and model) the following expressions of the Model Law were obtained (that is, the final expressions in which the corresponding scale factors $S_{\eta}$ of the dependent variables were defined in function of the scale factors of the independent variables):

$$
\begin{gathered}
\pi_{1}=\dot{Q} \cdot Q^{-1} \cdot L_{t}^{0} \cdot \Delta t^{0} \cdot \tau^{1} \cdot \lambda_{x \text { steel }}^{0} \cdot \varsigma^{0}=\frac{\dot{Q} \cdot \tau}{Q}=1 \Rightarrow \frac{S_{\dot{Q}} \cdot S_{\tau}}{S_{Q}}=1 \Rightarrow S_{\dot{Q}}=\frac{S_{Q}}{S_{\tau}}, \\
\pi_{2}: S_{A_{t r}}=\frac{S_{L_{t}}}{S_{\zeta}} \\
\pi_{3}: S_{A_{l a t}}=\frac{S_{Q} \cdot S_{L_{t}}}{S_{\Delta t} \cdot S_{\tau} \cdot S_{\lambda_{x} \text { steel }}} \\
\pi_{4}: S_{r_{c y l}}=\sqrt{\frac{S_{L_{t}}}{S_{\zeta}}}
\end{gathered}
$$




$$
\begin{aligned}
& \pi_{5}: S_{L_{x}}=\frac{S_{Q}}{S_{\Delta t} \cdot S_{\tau} \cdot S_{\lambda_{x s t e e l}}} \\
& \pi_{6}: S_{L_{r}}=\sqrt{\frac{S_{L_{t}}}{S_{\zeta}}}
\end{aligned}
$$

(b) From experiments on coated structures (prototype and model) the set of previous expressions is completed with expressions specific to the coating paint, which are $\left(\pi_{31} \ldots \pi_{35}\right)$. The following set of expressions of the Model Law is obtained $\left(\pi_{1} \ldots \pi_{6}\right)$ and $\left(\pi_{31} \ldots \pi_{35}\right)$.

$$
\begin{aligned}
& \pi_{1} S_{\dot{Q}}=\frac{S_{Q}}{S_{\tau}}, \\
& \pi_{2}: S_{A_{t r}}=\frac{S_{L_{t}}}{S_{\zeta}},
\end{aligned}
$$

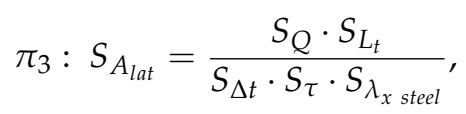

$$
\begin{aligned}
& \pi_{4}: S_{r_{c y l}}=\sqrt{\frac{S_{L_{t}}}{S_{\zeta}}}, \\
& \pi_{5}: S_{L_{x}}=\frac{S_{Q}}{S_{\Delta t} \cdot S_{\tau} \cdot S_{\lambda_{x s t e e l}}} \\
& \pi_{6}: S_{L_{r}}=\sqrt{\frac{S_{L_{t}}}{S_{\zeta}}}, \\
& \pi_{31}: S_{\rho_{\text {paint }}}=\frac{\left(S_{\Delta t}\right)^{3} \cdot\left(S_{\tau}\right)^{5} \cdot\left(S_{\lambda_{x ~ s t e e l}}\right)^{3} \cdot S_{\zeta}}{\left(S_{Q}\right)^{2} \cdot S_{L_{t}}}, \\
& \pi_{32}: S_{\lambda_{x p a i n t}}=S_{\lambda_{x \text { steel }}} \text {, } \\
& \pi_{33}: S_{\lambda_{r \text { paint }}}=\frac{S_{Q}}{S_{\Delta t} \cdot S_{\tau}} \cdot \sqrt{\frac{S_{\zeta}}{S_{L_{t}}}}, \\
& \pi_{34}: S_{\alpha_{n r} \text { paint }}=\frac{S_{\lambda_{x ~ s t e e l}}}{S_{L_{t}}} \\
& \pi_{35}: S_{\delta_{r \text { paint }}}=\sqrt{\frac{S_{L_{t}}}{S_{\zeta}}} .
\end{aligned}
$$

(c) For theoretical investigations of parameters dependence $\left(c_{p}\right.$ air $, C_{a i r}, C_{s t e e l}, a_{x}$ air, $\left.a_{r \text { air }}, \rho_{\text {air }}, \rho_{\text {steel }}, \lambda_{r_{\text {steel }}}, v_{x \text { air }}, v_{r \text { air }}, \alpha_{n x \text { steel }}, \alpha_{n r \text { steel }}, \eta_{x \text { air }}, \eta_{r \text { air }}, \beta_{\text {air } / \text { steel }}\right)$ on the set of independent variables (of prototype and model), the following set of expressions will be used $\left(\pi_{7} \ldots \pi_{21}\right)$ :

$$
\begin{gathered}
\pi_{7}: S_{\mathcal{C}_{p \text { air }}}=\frac{\left(S_{Q}\right)^{2}}{\left(S_{\Delta t}\right)^{3} \cdot\left(S_{\tau}\right)^{4} \cdot\left(S_{\left.\lambda_{x \text { steel }}\right)^{2}}\right.} \\
\pi_{8}: S_{C_{\text {air }}}=\frac{S_{Q}}{S_{\Delta t}} \\
\pi_{9}: S_{C_{\text {steel }}}=\frac{S_{Q}}{S_{\Delta t}} \\
\pi_{10}: S_{a_{x \text { air }}}=\frac{S_{L_{t}}}{S_{\tau} \cdot S_{\zeta}}
\end{gathered}
$$




$$
\begin{aligned}
& \pi_{11}: S_{a_{r_{\text {air }}}}=\frac{S_{Q}}{S_{\Delta t} \cdot\left(S_{\tau}\right)^{2} \cdot S_{\lambda_{x ~ s t e e l}}}, \\
& \pi_{12}: S_{\rho_{\text {air }}}=\frac{\left(S_{\Delta t}\right)^{3} \cdot\left(S_{\tau}\right)^{5} \cdot\left(S_{\lambda_{x \text { steel }}}\right)^{3} \cdot S_{\zeta}}{\left(S_{Q}\right)^{2} \cdot S_{L_{t}}},
\end{aligned}
$$

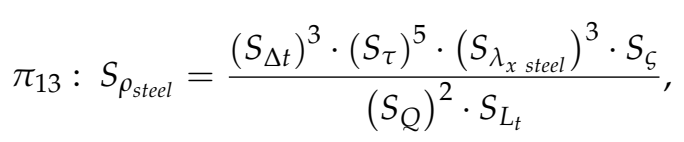

$$
\begin{aligned}
& \pi_{14}: S_{\lambda_{r \text { steel }}}=\frac{S_{Q}}{S_{\Delta t} \cdot S_{\tau}} \cdot \sqrt{\frac{S_{S}}{S_{L_{t}}}} \\
& \pi_{15}: S_{v_{x} \text { air }} \frac{S_{Q}}{S_{\Delta t} \cdot\left(S_{\tau}\right)^{2} \cdot S_{\lambda_{x \text { steel }}} \cdot S_{\zeta}}, \\
& \pi_{16}: S_{v_{r \text { air }}}=\frac{S_{Q}}{S_{\Delta t} \cdot\left(S_{\tau}\right)^{2} \cdot S_{\lambda_{x \text { steel }}}},
\end{aligned}
$$

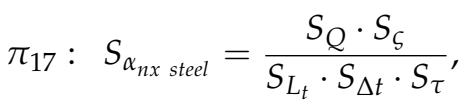

$$
\begin{aligned}
& \pi_{18}: S_{\alpha_{n r \text { steel }}}=\frac{S_{\lambda_{x \text { steel }}},}{S_{L_{t}}} \\
& \pi_{19}: S_{\eta_{x \text { air }}}=\frac{\left(S_{\Delta t}\right)^{2} \cdot\left(S_{\tau}\right)^{3} \cdot\left(S_{\lambda_{x \text { steel }}}\right)^{2}}{S_{Q} \cdot S_{L_{t}}}, \\
& \pi_{20}: S_{\eta_{r_{\text {air }}}}=\frac{\left(S_{\Delta t}\right)^{2} \cdot\left(S_{\tau}\right)^{3} \cdot\left(S_{\lambda_{x \text { steel }}}\right)^{2}}{S_{Q}} \cdot \sqrt{\frac{S_{S}}{S_{L_{t}}}}, \\
& \pi_{21}: S_{\beta_{\text {air } / \text { steel }}}=\frac{1}{S_{\Delta t}} .
\end{aligned}
$$

(d) For investigations of the dependence of the parameters on the set of independent variables and for setting of heat transfer correlations between dimensionless numbers based on the expressions of the model law (by combining them favorably), the next set of expressions $\left(\pi_{22} \ldots \pi_{30}\right)$ will be used:

$$
\begin{aligned}
& \pi_{22}: S_{C r i t 01}=\frac{S_{\Delta t} \cdot S_{\tau} \cdot S_{\lambda_{x \text { steel }}}}{S_{Q}} \cdot \sqrt{\frac{S_{L_{t}}}{S_{\zeta}}} \\
& \pi_{23}: S_{\text {Crit 02 }}=\frac{\left(S_{Q}\right)^{2} \cdot S_{\zeta}}{S_{L_{t}}\left(S_{\Delta t}\right)^{2} \cdot\left(S_{\tau}\right)^{2} \cdot\left(S_{\lambda_{\text {steel }}}\right)^{2}} \text {, } \\
& \pi_{24}: S_{\text {Crit } 03}=\frac{S_{\Delta t} \cdot S_{\tau} \cdot S_{\lambda_{x \text { steel }}}}{S_{Q} \cdot S_{\zeta}},
\end{aligned}
$$

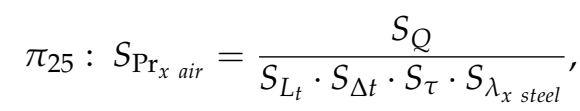

$$
\begin{aligned}
& \pi_{26}: S_{G r_{x \text { air }}}=\frac{\left(S_{Q}\right)^{2} \cdot\left(S_{\zeta}\right)^{2}}{\left(s_{\Delta t}\right)^{2} \cdot\left(S_{\tau}\right)^{2} \cdot\left(s_{\lambda_{x \text { steel }}}\right)^{2}} \text {, } \\
& \pi_{27}: S_{F o_{x} \text { air }}=\frac{S_{L_{t}} \cdot\left(S_{\Delta t}\right)^{2} \cdot\left(S_{\tau}\right)^{2} \cdot\left(S_{\lambda_{x \text { steel }}}\right)^{2}}{\left(S_{Q}\right)^{2} \cdot S_{\zeta}},
\end{aligned}
$$




$$
\begin{gathered}
\pi_{28}: S_{F o_{r \text { air }}}=\frac{S_{Q}}{S_{\Delta t} \cdot S_{\tau} \cdot S_{\lambda_{x \text { steel }}}} \cdot \sqrt{\frac{S_{\zeta}}{S_{L_{t}}}}, \\
\pi_{29}: S_{\operatorname{Re}_{x \text { air }}}=\frac{S_{Q} \cdot S_{\zeta}}{S_{\Delta t} \cdot S_{\tau} \cdot S_{\lambda_{x} \text { steel }}}, \\
\pi_{30}: S_{S t_{r_{\text {air }}}}=\frac{1}{\sqrt{S_{L_{t}} \cdot S_{\zeta}}} .
\end{gathered}
$$

In order to show how the elements of the model law can be applied for correlating the prototype with the model, the following variables were selected:

- $\quad$ heat rate $\dot{Q}_{1}$;

- $\quad$ model length $L_{x 2}$;

- thickness of the paint layer used for the model $\delta_{r} 2$ paint .

These variables are governed by relations (1), (17), and (35) of the model law.

As can be observed, $\dot{Q}_{1}$ is a quantity that refers to the prototype and cannot be measured, since experiments were carried out only on the model, while $L_{x} 2$ and $\delta_{r} 2$ paint are corresponding to the model and they can be determined only for the prototype; for the model they are obtained strictly from the elements of the model law.

Considering the set of independent variables, having the dimensions determined for both prototype and model, the scale factors $\left(S_{Q}, S_{L_{t}}, S_{\Delta t}, S_{\tau}, S_{\lambda_{\text {steel }}}, S_{\zeta}\right)$ are considered to be known, as well.

In order to obtain $\dot{Q}_{1}$, relation (1) is used, where the scale factor $S_{\dot{Q}}$ is the ratio between $\dot{Q}_{2}$ and $\dot{Q}_{1}$. Thus, the following is obtained:

$$
\pi_{1} S_{\dot{Q}}=\frac{S_{Q}}{S_{\tau}} \Leftrightarrow \frac{\dot{Q}_{2}}{\dot{Q}_{1}}=\frac{S_{Q}}{S_{\tau}} \Rightarrow \dot{Q}_{1}=\frac{S_{\tau}}{S_{Q}} \dot{Q}_{2}
$$

The model length $L_{x}$ is obtained from relation (17), as:

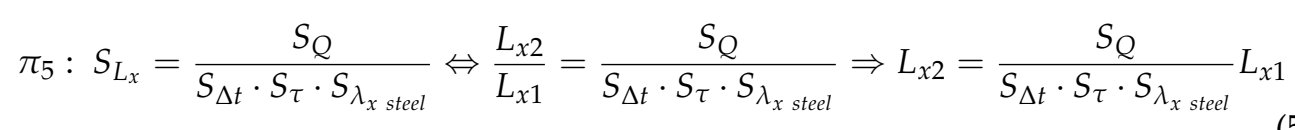
(29):

The thickness of the paint layer that covers the model $\delta_{r 2}$ paint is acquired from relation

$$
\pi_{35}: S_{\delta_{r p a i n t}}=\sqrt{\frac{S_{L_{t}}}{S_{\zeta}}} \Leftrightarrow \frac{\delta_{r 2 p a i n t}}{\delta_{r 1 \text { paint }}}=\sqrt{\frac{S_{L_{t}}}{S_{\zeta}}} \Rightarrow \delta_{r 2 \text { paint }}=\delta_{r 1 \text { paint }} \cdot \sqrt{\frac{S_{L_{t}}}{S_{\zeta}}} .
$$

Considering the previous relations, some observations can be made:

(a) The dependent variable $\dot{Q}_{1}$, which has to be determined for the prototype, cannot be excluded from the dimensional set or the model law.

(b) The other dependent variables of the model (here $L_{x 2}$ and $\delta_{r} 2$ paint $)$ can be analyzed without so many restrictions, considering the set of independent variables, namely:

- $\quad$ if the scale factor is the same for all lengths, then $S_{L_{t}}=S_{L_{x}}$, and consequently the relation of the fifth element of the model law, $\pi_{5}$ can be neglected.

- if the thickness of the paint is the same for the prototype and model, then the relation of $\pi_{35}$ to the model law can be omitted.

- if it is aimed to conceive a more flexible model, then the model law allows us to consider different scales of the lengths along directions $(x, r, t)$ or different thicknesses of the paint layer, but strictly considering the elements of the model law.

As can be noticed, this is another major advantage of $M D A$, which cannot be obtained if the aforementioned methods are used. 


\subsection{Second Case Study}

For the second significant version, II, where $Q$ was substituted by $Q$, the following significant elements of the dimensional set were obtained, according to Tables 7-11:

Table 7. Matrix A, comprising independent variables.

\begin{tabular}{ccccccc}
\hline Dimensions & $\dot{\boldsymbol{Q}}$ & $\boldsymbol{L}_{\boldsymbol{t}}$ & $\boldsymbol{\Delta} \boldsymbol{t}$ & $\boldsymbol{\tau}$ & $\lambda_{\boldsymbol{x} \text { steel }}$ & $\boldsymbol{\zeta}=\boldsymbol{P} / \boldsymbol{A}$ \\
\hline$m_{x}$ & 2 & 0 & 0 & 0 & 1 & 0 \\
\hline$m_{r}$ & 0 & 0 & 0 & 0 & 0 & -2 \\
\hline$m_{t}$ & 0 & 1 & 0 & 0 & 0 & 1 \\
\hline $\mathrm{kg}$ & 1 & 0 & 0 & 0 & 1 & 0 \\
\hline $\mathrm{s}$ & -3 & 0 & 0 & 1 & -3 & 0 \\
\hline${ }^{\circ} \mathrm{C}$ & 0 & 0 & 1 & 0 & -1 & 0 \\
\hline
\end{tabular}

Table 8. The quantities required by experiments (part of matrix B).

\begin{tabular}{ccccccc}
\hline Dimensions & $\boldsymbol{Q}$ & $\boldsymbol{A}_{\boldsymbol{t r}}$ & $\boldsymbol{A}_{\text {lat }}$ & $\boldsymbol{r}_{\boldsymbol{c y l}}$ & $\boldsymbol{L}_{\boldsymbol{x}}$ & $\boldsymbol{L}_{\boldsymbol{r}}$ \\
\hline$m_{x}$ & 2 & 0 & 1 & 0 & 1 & 0 \\
\hline$m_{r}$ & 0 & 2 & 0 & 1 & 0 & 1 \\
\hline$m_{t}$ & 0 & 0 & 1 & 0 & 0 & 0 \\
\hline $\mathrm{kg}$ & 1 & 0 & 0 & 0 & 0 & 0 \\
\hline $\mathrm{s}$ & -2 & 0 & 0 & 0 & 0 & 0 \\
\hline${ }^{\circ} \mathrm{C}$ & 0 & 0 & 0 & 0 & 0 & 0 \\
\hline
\end{tabular}

Table 9. The quantities required by the theoretical analysis (part of matrix B).

\begin{tabular}{|c|c|c|c|c|c|c|c|c|c|c|c|c|c|c|c|}
\hline Dimensions & $c_{p \text { air }}$ & $C_{a i r}$ & $C_{\text {steel }}$ & $a_{x \text { air }}$ & $a_{\text {rair }}$ & $\rho_{\text {air }}$ & $\rho_{\text {steel }}$ & $\overline{\lambda_{\text {rsteel }}}$ & $v_{x \text { air }}$ & $v_{\text {rair }}$ & $\alpha_{n x ~ s t e e l}$ & $\alpha_{n r \text { steel }}$ & $\eta_{x \text { air }}$ & $\eta_{\text {rair }}$ & $\beta_{\text {air/steel }}$ \\
\hline$m_{x}$ & 2 & 2 & 2 & 0 & 1 & -1 & -1 & 2 & 1 & 1 & 2 & 1 & 0 & 0 & 0 \\
\hline$m_{r}$ & 0 & 0 & 0 & 2 & 1 & -2 & -2 & -1 & 2 & 1 & -2 & 0 & 0 & -1 & 0 \\
\hline$m_{t}$ & 0 & 0 & 0 & 0 & 0 & 0 & 0 & 0 & -1 & 0 & 0 & -1 & -1 & 0 & 0 \\
\hline $\mathrm{kg}$ & 0 & 1 & 1 & 0 & 0 & 1 & 1 & 1 & 0 & 0 & 1 & 1 & 1 & 1 & 0 \\
\hline $\mathrm{s}$ & -2 & -2 & -2 & -1 & -1 & 0 & 0 & -3 & -1 & -1 & -3 & -3 & -1 & -1 & 0 \\
\hline${ }^{\circ} \mathrm{C}$ & -1 & -1 & -1 & 0 & 0 & 0 & 0 & -1 & 0 & 0 & -1 & -1 & 0 & 0 & -1 \\
\hline
\end{tabular}


Table 10. The quantities required by the heat transfer correlations between dimensionless numbers (part of matrix B).

\begin{tabular}{cccccccccc}
\hline Dimensions & Crit 01 & Crit 02 & Crit 03 & $\mathbf{P r}_{\text {xair }}$ & Gr $_{\text {xair }}$ & Fo $_{\text {xair }}$ & Fo $_{\text {rair }}$ & $\mathbf{R e}_{\text {xair }}$ & St $_{\text {rair }}$ \\
\hline$m_{x}$ & 1 & 2 & -1 & 0 & -1 & -2 & 1 & -1 \\
\hline$m_{r}$ & -1 & -2 & 2 & 0 & 1 & 2 & 0 & 0 \\
\hline$m_{t}$ & 0 & 0 & -1 & 0 & 0 & 0 & 0 & 1 \\
\hline $\mathrm{kg}$ & 0 & 0 & 0 & 0 & 0 & 0 & 0 & 0 \\
\hline $\mathrm{s}$ & 0 & 0 & 0 & 0 & 0 & 0 & -2 & 0 \\
\hline${ }^{\circ} \mathrm{C}$ & 0 & 0 & 0 & -1 & 0 & 0 & 0 & 0 \\
\hline
\end{tabular}

Table 11. The properties of the intumescent paint (part of matrix B).

\begin{tabular}{cccccc}
\hline & $\rho_{\text {paint }}$ & $\lambda_{\text {x paint }}$ & $\lambda_{\text {r paint }}$ & $\alpha_{\text {nr paint }}$ & $\delta_{r \text { paint }}$ \\
\hline$m_{x}$ & -1 & 1 & 2 & 1 & 0 \\
\hline$m_{r}$ & -2 & 0 & -1 & 0 & 1 \\
\hline$m_{t}$ & 0 & 0 & 0 & -1 & 0 \\
\hline $\mathrm{kg}$ & 1 & 1 & 1 & 1 & 0 \\
\hline $\mathrm{s}$ & 0 & -3 & -3 & -3 & 0 \\
\hline${ }^{\circ} \mathrm{C}$ & 0 & -1 & -1 & -1 & 0 \\
\hline
\end{tabular}

The corresponding elements of the model law are:

$$
\begin{aligned}
& \pi_{1}: S_{Q}=S_{\dot{Q}} \cdot S_{\tau} \\
& \pi_{2}: S_{A_{t r}}=\frac{S_{L_{t}}}{S_{\zeta}}, \\
& \pi_{3}: S_{A_{\text {lat }}}=\frac{S_{\dot{Q}} \cdot S_{L_{t}}}{S_{\Delta t} \cdot S_{\lambda_{x \text { steel }}}}, \\
& \pi_{4}: S_{r_{c y l}}=\sqrt{\frac{S_{L_{t}}}{S_{\zeta}}} \\
& \pi_{5}: S_{L_{x}}=\frac{S_{\dot{Q}}}{S_{\Delta t} \cdot S_{\lambda_{x \text { steel }}}}, \\
& \pi_{6}: S_{L_{r}}=\sqrt{\frac{S_{L_{t}}}{S_{\zeta}}}, \\
& \pi_{7}: S_{c_{p \text { air }}}=\frac{\left(S_{\dot{Q}}\right)^{2}}{\left(S_{\Delta t}\right)^{3} \cdot\left(S_{\tau}\right)^{2} \cdot\left(S_{\lambda_{x \text { steel }}}\right)^{2}} \text {, } \\
& \pi_{8}: S_{C_{a i r}}=\frac{S_{\dot{Q}} \cdot S_{\tau}}{S_{\Delta t}}, \\
& \pi_{9}: S_{C_{\text {steel }}}=\frac{S_{\dot{Q}} \cdot S_{\tau}}{S_{\Delta t}} \\
& \pi_{10}: S_{a_{x \text { air }}}=\frac{S_{L_{t}}}{S_{\tau} \cdot S_{\zeta}}, \\
& \pi_{11}: S_{a_{\text {r air }}}=\frac{S_{\dot{Q}}}{S_{\Delta t} \cdot S_{\tau} \cdot S_{\lambda_{x} \text { steel }}} \cdot \sqrt{\frac{S_{L_{t}}}{S_{\zeta}}},
\end{aligned}
$$




$$
\begin{aligned}
& \pi_{12}: S_{\rho_{\text {air }}}=\frac{\left(S_{\Delta t}\right)^{3} \cdot\left(S_{\tau}\right)^{3} \cdot\left(S_{\lambda_{x \text { steel }}}\right)^{3} \cdot S_{\zeta}}{\left(S_{\dot{Q}}\right)^{2} \cdot S_{L_{t}}}, \\
& \pi_{13}: S_{\rho_{\text {steel }}}=\frac{\left(S_{\Delta t}\right)^{3} \cdot\left(S_{\tau}\right)^{3} \cdot\left(S_{\lambda_{x \text { steel }}}\right)^{3} \cdot S_{\zeta}}{\left(S_{\dot{Q}}\right)^{2} \cdot S_{L_{t}}}, \\
& \pi_{14}: S_{\lambda_{r \text { steel }}}=\frac{S_{\dot{Q}}}{S_{\Delta t}} \cdot \sqrt{\frac{S_{\zeta}}{S_{L_{t}}}}, \\
& \pi_{15}: S_{v_{x} \text { air }}=\frac{S_{\dot{Q}}}{S_{\Delta t} \cdot S_{\tau} \cdot S_{\lambda_{x} \text { steel }} \cdot S_{\zeta}},
\end{aligned}
$$

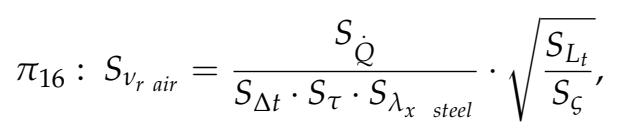

$$
\begin{aligned}
& \pi_{17}: S_{\alpha_{n x \text { steel }}} \frac{S_{\dot{Q}} \cdot S_{\zeta}}{S_{L_{t}} \cdot S_{\Delta t}}, \\
& \pi_{18}: S_{\alpha_{n r \text { steel }}}=\frac{S_{\lambda_{x \text { steel }}},}{S_{L_{t}}}, \\
& \pi_{19}: S_{\eta_{x} \text { air }}=\frac{\left(S_{\Delta t}\right)^{2} \cdot\left(S_{\tau}\right)^{2} \cdot\left(S_{\lambda_{x \text { steel }}}\right)^{2}}{S_{\dot{Q}} \cdot S_{L_{t}}}, \\
& \pi_{20}: S_{\eta_{r_{\text {air }}}}=\frac{\left(S_{\Delta t}\right)^{2} \cdot\left(S_{\tau}\right)^{2} \cdot\left(S_{\lambda_{x \text { steel }}}\right)^{2}}{S_{\dot{Q}}} \cdot \sqrt{\frac{S_{\zeta}}{S_{L_{t}}}}, \\
& \pi_{21}: S_{\beta_{\text {air } / \text { steel }}}=\frac{1}{S_{\Delta t}} .
\end{aligned}
$$

The mentioned dimensionless numbers have the same expressions:

$$
\begin{gathered}
C \text { rit } 01=\mathrm{Re}_{r}=P e_{r}=\frac{m_{x}}{m_{r}}, \\
C \text { rit } 02=N u_{x}=P e_{x}=B i_{x}=\frac{m_{x}^{2}}{m_{r}^{2}}, \\
C \text { rit } 03=N u_{r}=B i_{r}=\frac{m_{r}^{2}}{m_{x} \cdot m_{t}},
\end{gathered}
$$

The elements of the model law are:

$$
\begin{aligned}
& \pi_{22}: S_{\text {Crit } 01}=\frac{S_{\Delta t} \cdot S_{\lambda_{x} \text { steel }}}{S_{\dot{Q}}} \cdot \sqrt{\frac{S_{L_{t}}}{S_{\zeta}}}, \\
& \pi_{23}: S_{\text {Crit } 02}=\frac{\left(S_{\dot{Q}}\right)^{2} \cdot S_{\zeta}}{S_{L_{t}} \cdot\left(S_{\Delta t}\right)^{2} \cdot\left(S_{\lambda_{x} \text { steel }}\right)^{2}} \text {, } \\
& \pi_{24}: S_{\text {Crit 03 }}=\frac{S_{\Delta t} \cdot S_{\lambda_{x} \text { steel }}}{S_{\dot{Q}} \cdot S_{\zeta}},
\end{aligned}
$$

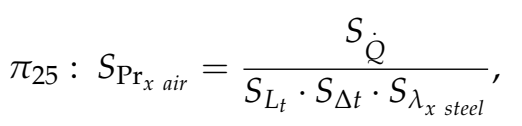




$$
\begin{gathered}
\pi_{26}: S_{G r_{x \text { air }}}=\frac{\left(S_{\dot{Q}}\right)^{2} \cdot\left(S_{\zeta}\right)^{2}}{\left(S_{\Delta t}\right)^{2} \cdot\left(S_{\lambda_{x} \text { steel }}\right)^{2}} \\
\pi_{27}: S_{F o_{x \text { air }}}=\frac{S_{L_{t}} \cdot\left(S_{\Delta t}\right)^{2} \cdot\left(S_{\lambda_{x} \text { steel }}\right)^{2}}{\left(S_{\dot{Q}}\right)^{2} \cdot S_{\zeta}}, \\
\pi_{28}: S_{F o_{r \text { air }}}=\frac{S_{\dot{Q}}}{S_{\Delta t} \cdot S_{\lambda_{x} \text { steel }}} \cdot \sqrt{\frac{S_{\zeta}}{S_{L_{t}}}}, \\
\pi_{29}: S_{\operatorname{Re}_{x_{\text {air }}}}=\frac{S_{\dot{Q}} \cdot S_{\zeta}}{S_{\Delta t} \cdot S_{\lambda_{x} \text { steel }}} \\
\pi_{30}: S_{S_{t_{\text {a air }}}}=\frac{1}{\sqrt{S_{L_{t}} \cdot S_{\zeta}}},
\end{gathered}
$$

The elements of the model law are:

$$
\begin{gathered}
\pi_{31}: S_{\rho_{\text {paint }}}=\frac{\left(S_{\Delta t}\right)^{3} \cdot\left(S_{\tau}\right)^{3} \cdot\left(S_{\lambda_{x \text { steel }}}\right)^{3} \cdot S_{\zeta}}{\left(S_{\dot{Q}}\right)^{2} \cdot S_{L_{t}}}, \\
\pi_{32}: S_{\lambda_{x \text { paint }}}=S_{\lambda_{x \text { steel }},} \\
\pi_{33}: S_{\lambda_{r \text { paint }}}=\frac{S_{\dot{Q}}}{S_{\Delta t}} \cdot \sqrt{\frac{S_{\zeta}}{S_{L_{t}}}} \\
\pi_{34}: S_{\alpha_{n r \text { paint }}}=\frac{S_{\lambda_{x \text { steel }}}}{S_{L_{t}}} \\
\pi_{35}: S_{\delta_{r \text { paint }}}=\sqrt{\frac{S_{L_{t}}}{S_{\zeta}}}
\end{gathered}
$$

\section{Discussion and Conclusions}

The relations deduced in the paper for the case of the straight bar of the full circular section can be applied without problems to the tubular (ring) bars, both to the resistance structures formed/constituted by them, as well as the reticular structures used in the roofs of industrial halls, gyms, etc.

In these cases, of the structures made of straight bar elements, on the prototype and on the model, the homologous points (and sections) will be identified, with the help of which the thermal stresses on the model will be transferred to the prototype using of the model law.

It is clear that the internationally recognized work and achievements of Sedov [23], as well as other notable scientists $[1-5,8,13,22,25-28,30]$, are not disputed in any way by the authors of this paper. However, a number of difficulties need to be highlighted in addressing the issue of dimensional analysis by them and other illustrious authors compared to the methodology developed by Szirtes, the author of the works [31,32] namely:

- the direct analysis of the differential relations that describe the phenomenon, in order to establish the dimensionless groups, does not always allow the unitary establishment of the complete set of these dimensionless groups;

- also, the classical methodology (CDA) is usually cumbersome and non-unitary, allowing different researchers to obtain different sets of dimensionless variables;

- in order to obtain these dimensionless groups, the authors of different works use, based on the application of Buckingham's theorem, either the normalization of the terms of the differential relations related to the phenomenon describing the phenomenon, or a rather arbitrary and unambiguous combination of variables involved in describing 
the phenomenon of the main measure (dimensions), which takes place in each author according to his own logic, so it is a non-unitary approach to the phenomenon. Thus, based on these approaches, different sets of dimensionless variables may result, which may even represent combinations of those deduced by other authors [36,38-47].

- the classical methodology, i.e., CDA, presupposes from the very beginning a deep knowledge of the phenomenon and of the differential relations that govern the phenomenon, which for an ordinary researcher represents an impediment;

- the classical methodology, including those presented in the papers $[22,23,25,27-30]$, does not explicitly allow highlighting from the very beginning of the set of independent variables or dependent variables, but applies a hard-to-follow (and often unexplained) logic of how these two sets were chosen;

- the involvement from the very beginning, in approaching with the help of the dimensional analysis of the phenomenon, of some very complicated differential relations whose analysis will eventually lead to the establishment of these dimensionless groups, discourages the vast majority of researchers/engineers from using a safe, unified, and simple way to approach the problem, as will happen with MDA;

On the contrary, the methodology, called MDA, developed by Szirtes [31,32], represents a unified approach, easy and particularly accessible to any engineer, without requiring deep/grounded knowledge of the phenomenon, but only reviewing all parameters/variables that could have any influence on it.

Here, they are defined, in a unitary and unambiguous way, on the basis of a clear and particularly accessible protocol/procedure:

- the set of main dimensions;

- the main variables (i.e., the independent ones), i.e., those that can be chosen a priori for both the prototype and the model;

- the dependent variables, i.e., those that can be chosen a priori only for the prototype, and for the model will result exclusively only through the rigorous application of the model law;

- the variables sought for the prototype, which cannot be obtained by direct measurements of the prototype, but only on the basis of the results of experimental investigations performed on the model and by the rigorous application of the model law;

- the complete set of dimensionless variables, without the existence of ambiguous variants, is unitary;

- $\quad$ here the independent variables of the dependent ones are clearly delimited from the very beginning, based on rigorous mathematical criteria, as well as on some practical criteria regarding the quantities that deserve and that can be determined/controlled by experimental measurements.

In the works $[36-40,42,46,47]$ the classical approach is applied to determining the exponents, which will define the dimensionless groups. Thus, they are used either for the normalization of the known differential relations or the evaluation of the main dimensions and later the establishment of some combinations of the variables in order to obtain dimensionless groups.

In the paper [41], the dimensionless groups are arbitrarily defined, based on a combination, according to their own logic.

The only paper in which approaches closer to MDA were found is paper [35], where the determination of exponents was based on the methodology presented in [43], but does not specify how to choose independent or dependent variables, which is a deficiency of the methodology presented in [43] by Langhaar. In contrast, in Szirtes's work, i.e., in [31,32], each time, these independent variables are rigorously chosen, taking into account how an experiment of the model can be conducted more easily, allowing the model to be designed as favorably as possible for the experiments. 
The author of the paper [44] uses the choice of independent and dependent variables but applies the standard methodology for determining exponents by solving the system of linear equations, which describes the phenomenon.

The main advantage of MDA in setting the content of these groups of variables is that the elimination of some variables from this whole set does not influence the ones that remain. In other words, the expressions of a certain set will not be influenced if some of the dependent variables are considered or not.

Accordingly, if the whole set of the variables specific to the beam coated with intumescent paint was conceived, representing 35 expressions that define the model law, a certain number of dependent variables can be neglected without affecting the rest of the expressions.

In the above-described protocols, the general cases are indicated, from which several particular cases can be obtained.

Moreover, if for the prototype and model, a certain variable has identical values, then they can be ignored due to the fact that their scale factor became $S_{\eta}=1$ and consequently one will resolve useful particular cases similarly with the following:

- $\quad$ if both prototype and model are made of the same material (here: steel), then one has $S_{\alpha_{n x \text { steel }}}=S_{\alpha_{n r \text { steel }}}=S_{\lambda_{x \text { steel }}}=S_{\lambda_{\text {rsteel }}}=S_{\rho_{\text {steel }}}=S_{C_{\text {steel }}}=S_{\beta_{\text {steel }}}=1$;

- if environmental conditions for experiments are the same (the experiments are performed in the same environments) then: $S_{c_{p \text { air }}}=S_{C_{a i r}}=S_{a_{x \text { air }}}=S_{a_{r_{\text {air }}}}=S_{\rho_{\text {air }}}=$ $S_{\eta_{x \text { air }}}=S_{\eta_{r_{\text {air }}}}=S_{v_{x_{\text {air }}}}=S_{v_{r_{\text {air }}}}=S_{\beta_{\text {air }}}=1$;

- $\quad$ if the coating materials are identical for both prototype and model, then $S_{\rho_{\text {paint }}}=$ $S_{\lambda_{x \text { paint }}}=S_{\lambda_{\text {r paint }}}=S_{\alpha_{n \text { r paint }}}=1$, i.e., the expression corresponding to the dimensionnless variables $\pi_{31}, \ldots, \pi_{35}$ are eliminated, maintaining only the last one, $\pi_{35}$;

- if the same scales for lengths are adopted, other simplifications of the expressions of the model law will be obtained

It is also important to mention that, using the MDA, the model can be differently conceived from the prototype (another material, another coat of paint, etc.), which reveals once again the incontestable advantages of the method proposed in $[30,31]$ as compared to the classical dimensional analysis;

Another conclusion is that for tubular sections, where the thickness of the tube is $\delta_{r}$, the expression of the model law corresponding to length $L_{r}$, which is identical to $r_{c y l}$, can be applied to the thickness of the tube too. Therefore, the model law is valid also for tubular sections if the same scale is adopted as for $L_{r}$ and $r_{c y l}$.

To the best knowledge of the present authors there are no studies reporting the application of the $M D A$ method to the heat transfer in circular bars.

Author Contributions: Conceptualization, B.-P.G., I.S. and D.S.; methodology, B.-P.G., I.S. and D.Ș.; software, B.-P.G.; validation, B.-P.G., I.S., D.Ș. and S.V.; formal analysis, B.-P.G., I.S. and D.Ș.; investigation, B.-P.G., I.S. and D.S,; resources, B.-P.G., I.S., D.S, and S.V.; data curation, B.-P.G., I.S. and D.S.; writing — original draft preparation, I.S.; writing—review and editing, B.-P.G., I.S., D.S. and S.V.; visualization, B.-P.G., I.S., D.S. and S.V.; supervision, B.-P.G., I.S., D.S,. and S.V.; project administration, I.S.; funding acquisition, B.-P.G., I.S., D.S, and S.V. All authors have read and agreed to the published version of the manuscript.

Funding: This research received no external funding. The APC was funded by the Transilvania University of Brasov.

Institutional Review Board Statement: Not applicable.

Informed Consent Statement: Not applicable.

Data Availability Statement: Not applicable.

Conflicts of Interest: The authors declare no conflict of interest. 


\section{References}

1. Schnittger, J.R. Dimensional Analysis in Design. J. Vib. Accoustic Stress Reliab. Des. Trans. ASME 1988, 110, 401-407. [CrossRef]

2. Carinena, J.F.; Santander, M. Dimensional Analysis. Adv. Electron. Electron Phys. 1988, 72, 181-258.

3. Canagaratna, S.G. Is dimensional analysis the best we have to offer. J. Chem. Educ. 1993, 70, 40-43. [CrossRef]

4. Bhaskar, R.; Nigam, A. Qualitative Physics using Dimensional Analysis. Artif. Intell. 1990, 45, 73-111. [CrossRef]

5. Romberg, G. Contribution to Dimensional Analysis. Inginieur. Arch. 1985, 55, 401-412. [CrossRef]

6. Coyle, R.G.; Ballicolay, B. Concepts and Software for Dimensional Analysis in Modeling. IEEE Trans. Syst. Man Cybern. 1984, 14, 478-487. [CrossRef]

7. Barr, D.I.H. Consolidation of Basics of Dimensional Analysis. J. Eng. Mech. ASCE 1984, 110, 1357-1376. [CrossRef]

8. Remillard, W.J. Applying Dimensional Analysis. Am. J. Phys. 1983, 51, 137-140. [CrossRef]

9. Martins, R.D.A. The Origin of Dimensional Analysis. J. Frankl. Inst. 1981, 311, 331-337. [CrossRef]

10. Gibbings, J.C. A Logic of Dimensional Analysis. J. Physiscs A Math. Gen. 1982, 15, 1991-2002. [CrossRef]

11. Szekeres, P. Mathematical Foundations of Dimensional Analysis and the Question of Fundamental Units. Int. J. Theor. Phys. 1978, 17, 957-974. [CrossRef]

12. Carlson, D.E. Some New Results in Dimensional Analysis. Arch. Ration. Mech. Anal. 1978, 68, 191-210. [CrossRef]

13. Gibbings, J.C. Dimensional Analysis. J. Phys. A Math. Gen. 1980, 13, 75-89. [CrossRef]

14. Jofre, L.; del Rosario, Z.R.; Iaccarino, G. Data-driven dimensional analysis of heat transfer in irradiated particle-laden turbulent flow. Int. J. Multiph. Flow 2020, 125, 103198. [CrossRef]

15. Alshqirate, A.A.Z.S.; Tarawneh, M.; Hammad, M. Dimensional Analysis and Empirical Correlations for Heat Transfer and Pressure Drop in Condensation and Evaporation Processes of Flow Inside Micropipes: Case Study with Carbon Dioxide $\left(\mathrm{CO}_{2}\right) . \mathrm{J}$. Braz. Soc. Mech. Sci. Eng. 2012, 34, 89-96.

16. Levac, M.L.J.; Soliman, H.M.; Ormiston, S.J. Three-dimensional analysis of fluid flow and heat transfer in single- and two-layered micro-channel heat sinks. Heat Mass Transf. 2011, 47, 1375-1383. [CrossRef]

17. Nakla, M. On fluid-to-fluid modeling of film boiling heat transfer using dimensional analysis. Int. J. Multiph. Flow 2011, 37, 229-234. [CrossRef]

18. Illan, F.; Viedma, A. Experimental study on pressure drop and heat transfer in pipelines for brine based ice slurry Part II: Dimensional analysis and rheological Model. Int. J. Refrig. Rev. Int. Froid 2009, 32, 1024-1031. [CrossRef]

19. Nezhad, A.H.; Shamsoddini, R. Numerical Three-Dimensional Analysis of the Mechanism of Flow and Heat Transfer in a Vortex Tube. Therm. Sci. 2009, 13, 183-196. [CrossRef]

20. Asgari, O.; Saidi, M. Three-dimensional analysis of fluid flow and heat transfer in the microchannel heat sink using additivecorrection multigrid technique. In Proceedings of the Micro/Nanoscale Heat Transfer International Conference, PTS A and B. 1st ASME Micro/Nanoscale Heat Transfer International Conference, Tainan, Taiwan, 6-9 January 2008; pp. 679-689.

21. Carabogdan, G.I. Methods of Analysis of Thermal Energy Processes and Systems; Tehn: Bucharest, Romania, 1989.

22. Baker, W.E.; Westine, P.S.; Dodge, F.T. Similarity Methods in Engineering Dynamics; Elsevier: Amsterdam, The Netherlands, 1991.

23. Sedov, I.L. Similarity and Dimensional Methods in Mechanics; MIR Publisher: Moscow, Russia, 1982.

24. Sova, M.; Sova, D. Thermotechnics, Vol.II; Transilvania University Press: Brasov, Romania, 2001.

25. Zierep, J. Similarity Laws and Modelling; Marcel Dekker: New York, NY, USA, 1971.

26. Chen, W.K. Algebraic Theory of Dimensional Analysis. J. Frankl. Inst. 1971, 292, 403. [CrossRef]

27. Barenblatt, G.I. Dimensional Analysis; Gordon and Breach: New York, NY, USA, 1987.

28. Bridgeman, P.W. Dimensional Analysis; Reissued in Paperbound in 1963; Yale University Press: New Haven, CT, USA, 1922.

29. Buckingham, E. On Physically Similar Systems. Phys. Rev. 1914, 4, 345. [CrossRef]

30. Quintier, G.J. Fundamentals of Fire Phenomena; John Willey \& Sons: Hoboken, NJ, USA, 2006.

31. Szirtes, T.H. The Fine Art of Modelling. SPAR J. Eng. Technol. 1992, 1, 37.

32. Szirtes, T.H. Applied Dimensional Analysis and Modelling; McGraw-Hill: Toronto, ON, Canada, 1998.

33. Trif, I.; Asztalos, Z.; Kiss, I.; Élesztős, P.; Száva, I.; Popa, G. Implementation of the Modern Dimensional Analysis in Engineering Problems; Basic Theoretical Layouts. Ann. Fac. Eng. Hunedoara 2019, 17, 73-76.

34. Száva, I.; Szirtes, T.H.; Dani, P. An Application of Dimensional Model Theory in The Determination of the Deformation of a Structure. Eng. Mech. 2006, 13, 31-39.

35. Allamsettya, S.; Mohapatro, S. Prediction of $\mathrm{NO}$ and $\mathrm{NO}_{2}$ Concentrations in Ozone Injected Diesel Exhaust after NTP Treatment Using Dimensional Analysis. In Proceedings of the 10th International Conference on Applied Energy (ICAE2018), Hong Kong, China, 22-25 August 2018; pp. 4579-4585.

36. Phate, M.R.; Toney, S.B. Modeling and prediction of WEDM performance parameters for Al/SiCp MMC using dimensional analysis and artificial neural network. Eng. Sci. Technol. Int. J. 2019, 22, 468-476. [CrossRef]

37. Zhang, X.; Taira, H.; Liu, H. Error of Darcy's law for serpentine flow fields: Dimensional analysis. J. Power Sources 2019, 412, 391-397. [CrossRef]

38. He, Q.; Suorineni, F.T.; Ma, T.; Oh, J. Parametric study and dimensional analysis on prescribed hydraulic fractures in cave mining. Tunn. Undergr. Space Technol. 2018, 78, 47-63. [CrossRef]

39. Ashikhmin, V.N.; Kugaevskii, S.S. Dimensional Analysis in the Machining of Housing Components with Cast Holes. Russ. Eng. Res. 2013, 33, 509-513. [CrossRef] 
40. Almeida, R.S.M.; Al-Qureshib, H.A.; Tushteva, K.; Rezwan, K. On the dimensional analysis for the creep rate prediction of ceramic fibers. Ceram. Int. 2018, 44, 15924-15928. [CrossRef]

41. Yao, S.; Yan, K.; Lu, S.; Xu, P. Prediction and application of energy absorption characteristics of thinwalled circular tubes based on dimensional analysis. Thin-Walled Struct. 2018, 130, 505-519. [CrossRef]

42. Ferro, V. Assessing flow resistaance law in vegetated channels by dimenisonal aalysis and self-similarity. Flow Meas. Instrum. 2019, 69, 101610. [CrossRef]

43. Langhaar, H.L. Dimensional Analysis and Theory of Models; John Wiley \& Sons Ltd.: New York, NY, USA, 1951.

44. Kivade, S.B.; Murthy, C.S.N.; Vardhan, H. The use of Dimensional Analysis and Optimisation of Pneumatic Drilling Operations and Operating Parameters. J. Inst. Eng. India Ser. D 2012, 93, 31-36. [CrossRef]

45. Pankhurst, R.C. Dimensional Analysis and Scale Factor; Chapman \& Hall Ltd.: London, UK, 1964.

46. Khan, M.A.; Shah, I.A.; Rizvi, Z.; Ahmad, J. A numerical study on the validation of thermal formulations towards the behaviours of RC beams. Sci. Mater. Today Proc. 2019, 17, 227-234. [CrossRef]

47. Yen, P.H.; Wang, J.C. Power generation and electrical charge desnity with temperature effect of alumina nanofluids using dimensional analysis. Energy Convers. Manag. 2019, 186, 546-555. [CrossRef] 